\title{
Influence of frontal cyclone evolution on the 2009 (Ekman) and 2010 (Franklin) Loop Current eddy detachment events
}

\author{
Y. S. Androulidakis ${ }^{1, *}$, V. H. Kourafalou ${ }^{1}$, and M. Le Hénaff ${ }^{1}$ \\ ${ }^{1}$ University of Miami, Rosenstiel School of Marine and Atmospheric Science (RSMAS/MPO 4600), Rickenbacker Cswy, \\ Miami, FL 33149, USA \\ * now at: Laboratory of Maritime Engineering and Maritime Works, Civil Engineering Department, Aristotle University of \\ Thessaloniki, 54124, Thessaloniki, Greece \\ Correspondence to: Y. S. Androulidakis (iandroul@civil.auth.gr)
}

Received: 5 June 2014 - Published in Ocean Sci. Discuss.: 31 July 2014

Revised: 29 September 2014 - Accepted: 24 October 2014 - Published: 27 November 2014

\begin{abstract}
The anticyclonic Loop Current Eddy (LCE) shedding events are strongly associated with the evolution of Loop Current Frontal Eddies (LCFEs) over the eastern Gulf of Mexico (GoM). A numerical simulation, in tandem with in situ measurements and satellite data, was used to investigate the Loop Current (LC) evolution and the surrounding LCFE formation, structure, growth and migration during the Eddy Ekman and Eddy Franklin shedding events in the summers of 2009 and 2010, respectively. During both events, northern GoM LCFEs appeared vertically coherent to at least $1500 \mathrm{~m}$ in temperature observations. They propagated towards the base of the LC, where, together with the migration of Campeche Bank (southwest GoM shelf) eddies from south of the LC, contributed to its "necking-down". Growth of Campeche Bank LCFEs involved in Eddy Franklin was partially attributed to Campeche Bank waters following upwelling events. Slope processes associated with such upwelling included offshore exports of high positive potential vorticity that may trigger cyclone formation and growth. The advection and growth of LCFEs, originating from the northern and southern GoM, and their interaction with the LC over the LCE detachment area favor shedding conditions and may contribute to the final separation of the LCE.
\end{abstract}

\section{Background}

The Loop Current (LC) is the fraction of the North Atlantic western boundary current inside the Gulf of Mexico (GoM), which carries waters from the Caribbean Sea that enter the southern GoM from the Yucatan Channel. Anticyclonic rings, shed by the LC, are usually formed over the eastern GoM region and circulate warmer and more saline waters than the surrounding GoM waters, as they propagate westward into the GoM. The LC exits the GoM through the Straits of Florida, forming the Florida Current (FC) and feeding the Gulf Stream over the western and northern Atlantic (Sturges and Evans, 1983). The LC-FC system is the major connectivity pathway between the Caribbean Sea and the North Atlantic Ocean. This connectivity is thus strongly influenced by changes in the LC extension inside the GoM and especially by the shedding of the anticyclonic ring, or Loop Current Eddy (LCE), from the LC main body (e.g., Oey et al., 2005). The ring shedding processes were first referred to by Ichiye (1962) and studied with numerical modeling 20 years later by Hurlburt and Thompson (1982). In many LCE formation sequences, the LCE reattaches to the main LC body and detaches several times, before its final separation and westward propagation toward the western GoM (Sturges and Leben, 2000; see also detailed discussion in Schmitz Jr., 2005). Furthermore, dismemberments of the westward-propagating LCEs may also take place. These temporary detachments and full separations are largely influenced by cyclonic eddies (Biggs et al., 1996), also known as Loop Current Frontal Eddies (LCFEs; Fratantoni et al., 1998), associated with the LC front. The LC and associated LCEs and LCFEs are the main factors influencing the GoM mesoscale variability.

The LCE shedding events are related to various oceanographic and atmospheric conditions, before and during the 
separation period. The intrusion of the LC, toward the northwestern GoM, is a basic requirement for the potential separation of warm-core eddies (Schmitz Jr., 2005). Chérubin et al. (2005) found that the LCE separation process is related to LC instability. Using numerical modeling, Ezer et al. (2003) related the eddy shedding events to variability in the transport intensity of the Yucatan Current. In addition to the potential effect of the transport, observations showed that the shedding of LCEs is preceded by periods of diminished negative horizontal vorticity flux into the GoM (Candela et al., 2002). The effect of remote winds was studied by Oey (1996) and Chang and Oey (2012), who argued that the weakening of the wind over the Caribbean Sea leads to the decrease of the Yucatan transport, providing favorable conditions for the separation of the LCE. The separation of the LCE thus appears as the combination of various processes, both locally and remotely.

Von Arx et al. (1955) were the first to mention the presence of cyclonic eddies in the GoM region, but the role of these cold, cyclonic eddies in the LCE formation was first discussed by Cochrane (1972), based on in situ data. The system formed between the LC and the associated eddy field is a complex one, where cyclonic LCFEs and the anticyclonic LC or LCE influence each other. The synergy between the peripheral LCFE cyclones and the LC - and their relation with the LC northward propagation, contraction, detachments, and final separation of the LCE anticyclone have been highlighted in several studies (e.g., Kenelly et al., 1985; Zavala-Hidalgo et al., 2003; Schmitz Jr., 2005; Chérubin et al., 2005, 2006; Le Hénaff et al., 2012a). Around the LC, various types of cyclonic LCFEs interact with the LC and influence its propagation inside the GoM. Following Schmitz Jr. (2005), the first group of LCFEs consists of the cyclones west and south of the LC, along the Campeche Bank (southwest GoM shelf), thus forming the CB group. They usually move northward towards the central GoM and sometimes intrude into the LCE separation area over the deep eastern GoM (Zavala-Hidalgo et al., 2003; Athié et al., 2012). The cyclones along the northern edge of the LC form the second group (hereafter $\mathrm{N}$ Group) of eddies around the LC front. These cyclones appear to be affected by local topography that favors eddy intensification, due to the bottom of the northern GoM shelf slope (Le Hénaff et al., 2012a), and by local eddy merging (Walker et al., 2011; Le Hénaff et al., 2012a). These studies illustrated how such LCFEs can play a role in an LCE shedding sequence. A third group of LCFEs consists of eddies along the eastern side of the extended LC, along the west Florida Shelf. These have long been considered as the main LCFEs driving the LCE shedding (Vukovich and Maul, 1985), until long series of observations, mostly based on remote sensing, showed the full complexity of this process and the involvement of LCFEs from all above groups (Schmitz Jr., 2005). LCFEs may cover a large part of the water column (Cochrane, 1972). Moreover, several cyclones have been observed and simulated numerically over the deeper layers $(>1000 \mathrm{~m})$; these also interact with the LC evolution and its shedding events (Hamilton et al., 2011; Oey, 2008). An important site for the formation of these deep cyclones is the area north of Campeche Bank, around $23.5-25^{\circ} \mathrm{N}, 87-88^{\circ} \mathrm{W}$ (Oey, 2008).

\section{Study objectives}

We investigate the contribution of LCE to major LCFE shedding events during the summers of 2009 (Eddy Ekman event) and 2010 (Eddy Franklin event). In particular, we seek to identify the major cyclones that participated in the detachment processes; examine their sub-surface characteristics; and investigate the conditions that contribute to their advection, growth, and/or intensification. Both study periods are characterized by a marked LC intrusion into the northern Gulf of Mexico (NGoM), and several detachments preceding the formation of an anticyclonic eddy and southward retreat of the Loop Current main body (Hamilton et al., 2011). Eddy Ekman formed during the summer of 2009 and finally separated on 10 September 2009 , when it started moving toward the western gulf; the separation led to an extensive retreat of the Loop Current main body to $24.74^{\circ} \mathrm{N}$ (Hamilton et al., 2011). The detachment and separation events of summer 2010 led to the formation of Eddy Franklin, which played an important role in the Deepwater Horizon oil spill extension (Walker et al., 2011; Le Hénaff et al., 2012b). Eddy Franklin detached and reattached several times before it finally separated from the Loop Current on 29 September 2010. Hamilton et al. (2011) showed that deep cyclones north of the Yucatan Peninsula (CB Group) might have participated in the shedding sequence of Eddy Franklin.

Here, we examine the identification of the LCFE tracks and their synergy during the detachment and separation periods with the use of simulation results from a regional model, aided by satellite altimetry, satellite sea surface temperature (SST), and in situ measurements. We use a unique data set of buoys located along the US-Mexico boundary of the exclusive economic zone (EEZ; Fig. 1), over the area where the Loop Current extends and LCEs tend to detach (Hamilton et al., 2011). The buoys also cover some of the pathways of $\mathrm{N}$ Group cyclones.

The main goal of this study is to investigate the Loop Current spatial and temporal evolution under the influence of the complex eddy field and, in particular, specific processes that affected the shedding sequence during the summers of 2009 and 2010. We examine the evolution and vertical structure of the deep N Group cyclones, which are partially covered by the in situ data set, and their connection with the Loop Current vertical structure. We study the evolution of a Campeche Bank eddy, taking into account the contribution of local atmospheric forcing over the Campeche Bank, a connection which has not been previously explored. The two study periods cover the Eddy Ekman event (10-30 August 2009) and the Eddy Franklin event (20 June to 15 July 2010). These 


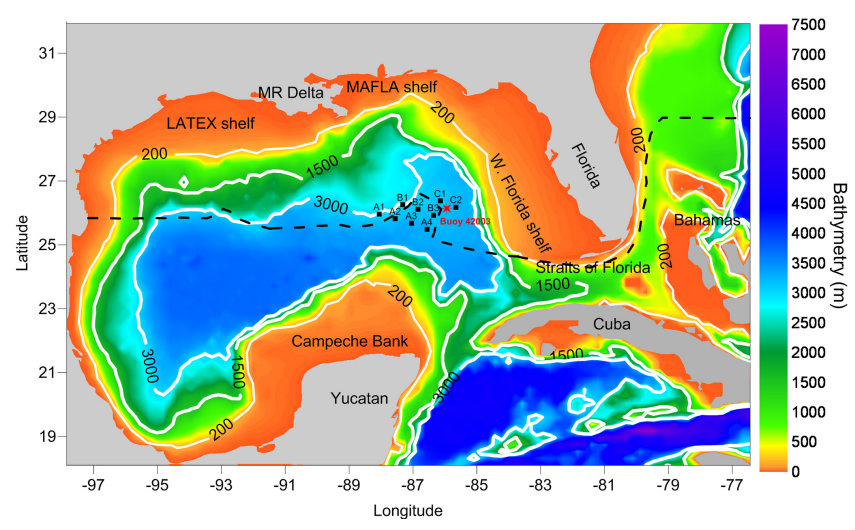

Figure 1. The Gulf of Mexico (GoM) bathymetry (contours in m) and GoM-HYCOM model domain. Black square dots mark the tall mooring deployment sites. The red star indicates the NOAA 42003 Buoy. White lines are the 200, 1500, and $3000 \mathrm{~m}$ isobaths. The black dashed line is the US-Mexico boundary of the exclusive economic zone. Shelf areas: Campeche Bank, LATEX (Louisiana-Texas) shelf, MAFLA (Mississippi-Alabama-Florida) shelf, west Florida shelf. Land areas: Yucatan Peninsula, Florida Peninsula, Bahamas islands, Cuba island. The Straits of Florida are between Florida, Cuba, and the Bahamas.

periods include major detachments before the final separations of Eddy Ekman and Eddy Franklin (which took place in September of each year). We seek to address three main questions related to the role of the frontal cyclones during the two shedding periods:

- What was the evolution of the Loop Current Frontal Eddies, and how did they relate to the Eddy Ekman and Eddy Franklin shedding sequences?

- What are the characteristics of the vertical structure for N Group Loop Current Frontal Eddies?

- Is the CB Group Eddy evolution influenced by local atmospheric forcing and shelf slope exchanges?

Section 3 describes the work methods comprising the model characteristics, the in situ measurements, and the satellite data. The model evaluation with available observations is presented in Sect. 4. Section 5 discusses the evolution of the Loop Current, the associated eddy field during Eddy Ekman and Eddy Franklin shedding events, the vertical characteristics and structure of the N Group cyclones, and the influence of environmental conditions on CB Group cyclone evolution, during the Loop Current Eddy detachment events of 2009 and 2010. Section 6 provides a summary and concluding remarks.

\section{Methodology}

\subsection{Model simulations}

The regional Gulf of Mexico Hybrid Coordinate Ocean Model (GoM-HYCOM; www.hycom.org) has been run in near-real time at the Naval Oceanographic Office (NAVOCEANO) since 2004, assimilating daily available near-realtime data through the Navy's Code for Data Assimilation (NCODA; Cummings, 2005). Since in situ data are usually quite sparse in the Gulf of Mexico (in particular, very few Argo floats reach the GoM), the data assimilation is mostly driven by remotely sensed observations (satellite altimetry and SST). Moreover, the 2010 simulation has benefited from the assimilation of in situ data associated with the monitoring of the Deepwater Horizon oil spill. However, data from the Loop Current buoy program (see Sect. 3.2) were not assimilated (as not available in real time during the simulation); therefore, this is a suitable data set for our modelindependent analyses (see Sect. 4). We note that the buoy program is independent from the monitoring of the Deepwater Horizon accident, it started in 2009 and it was not designed to report in real time. GoM-HYCOM was first employed to examine the evolving three-dimensional GoM response to Hurricane Ivan during 14-16 September 2004 (Prasad and Hogan, 2007; Zamudio and Hogan, 2008). Since then, it has been used in several GoM simulation studies, either providing boundary and initial conditions to shelf models (Schiller et al., 2011; Kourafalou and Kang, 2012; Androulidakis and Kourafalou, 2013) or investigating physical or biological processes of the entire GoM region (Mariano et al. 2011; Le Hénaff et al., 2012b; Paris et al., 2012; Valentine et al., 2012).

The GoM-HYCOM has a resolution of $1 / 25^{\circ}(\sim 4 \mathrm{~km})$ and extends from 77.36 to $98^{\circ} \mathrm{W}$ and from 18.09 to $30.71^{\circ} \mathrm{N}$ (Fig. 1) with 20 hybrid layers in the vertical (Prasad and Hogan, 2007; Kourafalou et al., 2009). The hybrid coordinate system is a unique capability of the HYCOM code (hycom.org), especially suitable for topographically complex areas, such as the GoM. The minimum and maximum depths are $2 \mathrm{~m}$ near the coastline and $7814 \mathrm{~m}$ south of Cuba, respectively (Fig. 1). GoM-HYCOM uses boundary conditions over the Caribbean and Atlantic boundaries from a simulation of the $1 / 12^{\circ}$ North Atlantic HYCOM, performed during the Global Data Assimilation Experiment (GODAE; see Kourafalou et al., 2009). The atmospheric forcing fields ( $10 \mathrm{~m}$ wind speed, vector wind stress, $2 \mathrm{~m}$ air temperature, $2 \mathrm{~m}$ atmospheric humidity, surface short- and longwave heat fluxes, and precipitation) are extracted from 3-hourly Navy Operational Global Atmospheric Prediction System (NOGAPS) reanalysis product (see Prasad and Hogan, 2007). The vertical mixing parameterization is based on the NASAGISS (Goddard Institute for Space Studies) Level 2 turbulence closure scheme (Canuto et al., 2001, 2002). The 2009-2010 period of the realistically forced GoM-HYCOM 
Table 1. Location (longitude and latitude) and maximum depth (m) of the moorings along the US-Mexico boundary of the EEZ.

\begin{tabular}{cccc}
\hline & $\begin{array}{c}\text { Lon } \\
\left({ }^{\circ} \mathrm{W}\right)\end{array}$ & $\begin{array}{c}\text { Lat } \\
\left({ }^{\circ} \mathrm{N}\right)\end{array}$ & $\begin{array}{c}\text { Maximum Depth } \\
(\mathrm{m})\end{array}$ \\
\hline $\mathrm{A} 1$ & 88.05 & 25.96 & 2935 \\
$\mathrm{~A} 2$ & 87.55 & 25.82 & 3100 \\
$\mathrm{~A} 3$ & 87.05 & 25.68 & 3193 \\
$\mathrm{~A} 4$ & 86.56 & 25.49 & 3162 \\
$\mathrm{~B} 1$ & 87.32 & 26.25 & 2949 \\
$\mathrm{~B} 2$ & 86.84 & 26.11 & 3032 \\
$\mathrm{~B} 3$ & 86.36 & 25.93 & 3056 \\
$\mathrm{C} 1$ & 86.14 & 26.38 & 3082 \\
$\mathrm{C} 2$ & 85.65 & 26.18 & 3150 \\
\hline
\end{tabular}

simulation has been employed to analyze the LCE shedding events, focusing on the LCFE evolution.

\subsection{Observations}

LCE detachments and separations usually take place over the central, deep part of the eastern GoM, along the US-Mexico boundary of the EEZ boundary; this guided the position of the 2009-2011 LC study moorings (Hamilton et al., 2011). In situ measurements of temperature, salinity, pressure, and current velocities were derived from several stations from a grid of nine full-depth sub-surface moorings (Fig. 1), covering the study period from April 2009 to July 2010; it is noted that these data are not assimilated in the model. The location and the maximum depth of each mooring are presented in Table 1 . The locations of the moorings cover an area of about $13000 \mathrm{~km}^{2}$ and a perimeter of almost $640 \mathrm{~km}$. The nine tall moorings carry point temperature sensors at 75, 150, 250, $350,525,600,750,900,1100,1300$, and $2000 \mathrm{~m}$ depth and $100 \mathrm{~m}$ above the bottom $(\sim 3000 \mathrm{~m})$. The temporal resolution of this data set is 60 minutes, producing very dense time series. The moorings cover the main region of the $\mathrm{N}$ Group cyclone pathways and interaction with the LC during both Eddy Ekman and Eddy Franklin periods, offering detailed information about their vertical structure and migration (see Sect. 5.3).

Maps of Absolute Dynamic Topography (ADT), derived from the AVISO data set (http://www.aviso.oceanobs.com/) were extracted for the summers of 2009 and 2010, for comparison to model Sea Surface Height (SSH) fields during the Eddy Ekman and Eddy Franklin shedding periods. AVISO weekly ADT maps with resolution of $1 / 3^{\circ}$ are the sum of the sea level anomaly, calculated from altimetry measurements, and the mean dynamic topography, evaluated from historical in situ data sets and other data (Rio et al., 2011). The mean dynamic topography is an essential component for capturing dynamical features whose time average has intense signature, such as the incoming flow in the Yucatan Channel or the Florida Current. In addition, SST satellite data produced by NASA's Advanced Microwave Scanning Radiometer (AMSR) were also used to evaluate the respective GoM-HYCOM SST and to detect specific surface features related to temperature, such as coastal upwelling events (see Sect. 5.4.1). The GoM-HYOM model (as Oceanic General Circulation Models generally do) assimilates along-track altimetric, and not the AVISO mapped data. The AVISO ADT maps are projected from the original along-track data. The assimilated altimetry data and AVISO maps are thus not the same product. Of course, since along-track altimetry is assimilated, one expects common features with AVISO maps, but not necessarily a perfect match, as the interpolation that leads to AVISO maps also makes hypotheses on the data and might degrade part of the information. Therefore, we have two altimetric data sets, one that is assimilated (along track) and one that can be used for analyses (AVISO).

\section{Model evaluation during Eddy Ekman and Eddy Franklin shedding sequences}

The in situ temperature measurements (Sect. 3.2) were compared to the GoM-HYCOM-simulated values (Sect. 3.1) at the mooring locations, during the summers of 2009 and 2010. The model-in situ data comparison is based on identifying sudden changes in the temperature evolution. Following the focus of this study, the formation and propagation of the LCFE (cold) and LCE (warm) eddies were compared and contrasted, as they are well characterized by their temperature. The GoM-HYCOM performance has been evaluated in previous studies (e.g., Kourafalou et al., 2009). Here, we focus on the model performance over the LCE detachment area, during the two study periods. The evolution of daily model and in situ temperature at 75 and $150 \mathrm{~m}$ of the A1 and $\mathrm{C} 1$ moorings (Fig. 1) is presented in Fig. 2. A1 and C1 are the most western and northern moorings, capturing the LCFE intrusions into the mooring grid, from west and north, respectively.

The simulated temperature evolution for all cases follows most of the major highs and lows of the measured time series, generally exhibiting a satisfactory agreement in temperature variability tendencies, keeping in mind the challenge of a point-to-point comparison (Fig. 2). It is noted that the comparison is performed at 75 and $150 \mathrm{~m}$ depth, i.e., below the mixed layer. Since the assimilation of SST fields into the model mostly impacts its surface temperature, the analysis of the model temperature at these depths is relevant for evaluating the model performance beyond the direct influence of data assimilation. The sharp temperature increase at $75 \mathrm{~m}$ during June 2009 and the high warm temperatures $\left(>24^{\circ} \mathrm{C}\right)$ at the end of July and August are simulated by the GoMHYCOM simulation (Fig. 2; Station A1). As presented in Fig. 5a, LC was extended over the central and north Gulf covering gradually the entire grid with buoys. Eventually, around mid-June 2009 it also covered the westernmost A1 buoy and 


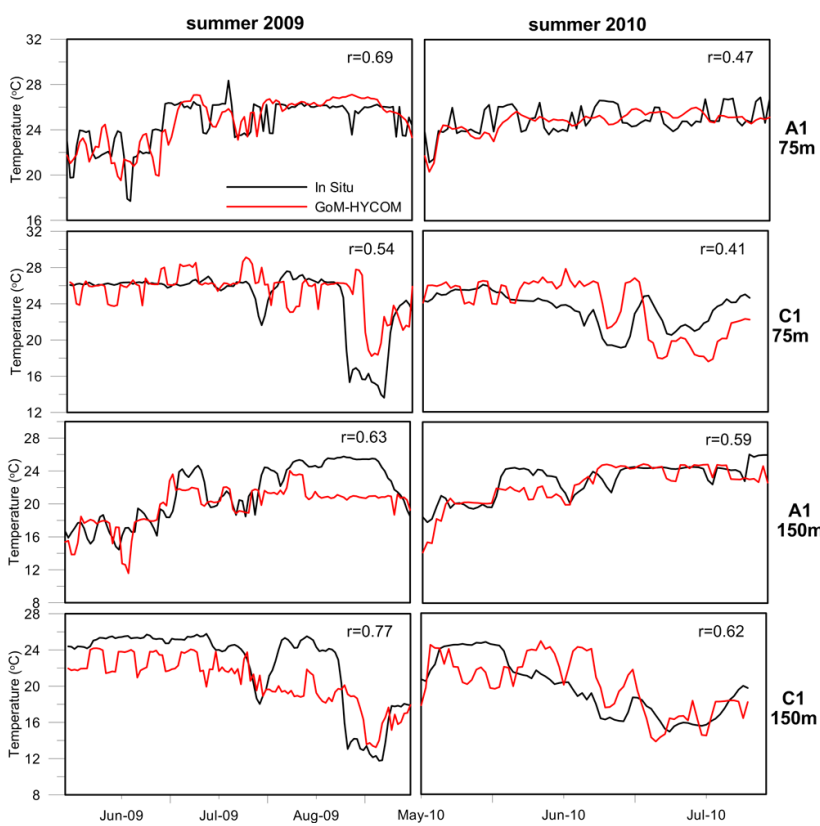

Figure 2. Daily GoM-HYCOM (red) and in situ (black) temperature time series for the summers of 2009 (left) and 2010 (right) at $75 \mathrm{~m}$ (top panels) and $150 \mathrm{~m}$ (bottom panels), at the $\mathrm{A} 1$ and $\mathrm{C} 1$ moorings (single model node closest to mooring position used). The correlation coefficients between the two time series $(r)$ are also presented for each case.

thus the temperature increased, as derived from both model and in situ time series (Fig. 2). In addition, the north side of the grid (Fig. 2; Station $\mathrm{C} 1$ ) revealed a strong temperature low $\left(\sim 16^{\circ} \mathrm{C}\right)$ during August 2009 , apparent in both modeled and observational data, indicating the intrusion of a cyclonic cold eddy from the north (see Sects. 5.2 and 5.3). This specific temperature effect was also observed over greater depths $(\mathrm{C} 1,150 \mathrm{~m})$. Both model and observations show very low values $\left(\sim 12^{\circ} \mathrm{C}\right)$ during mid-August 2009 (Eddy Ekman period) along the northern boundary of the moorings grid. Almost all Pearson correlation coefficients (Pearson, 1903) between model and observations of the two study periods for both stations and both depths are generally higher than 0.50; especially at the $\mathrm{C} 1150 \mathrm{~m}$ depth during summer 2009 , the correlation is significantly high $(r=0.77)$. The lowest correlation $(r=0.41)$ was calculated for the upper layer $(75 \mathrm{~m})$ of the $\mathrm{C} 1$ mooring during summer 2010. In general, the data and model patterns are in good agreement. Moreover, the lowerlevel temperature at mooring $\mathrm{C} 1(150 \mathrm{~m})$ reveals high correlation between model and observations during June 2010 (Eddy Franklin period, $r=0.62$ ), showing a trend to lower temperature, which is related to the intrusion of a cold cyclonic eddy from the north (see Sects. 5.2 and 5.3). Both model and data depict the different water masses surrounding $\mathrm{A} 1$ and $\mathrm{C} 1$ during the two events.
The detachments of the LCE rings from the main LC system during the two study periods are apparent in both model simulations and AVISO satellite altimetry products (Fig. 3); these satellite altimetry data are also not assimilated in the model. The simulated SSH at the end of August 2009 and in the beginning of July 2010 show high sea level elevations associated with Eddy Ekman and Eddy Franklin, respectively, both located over the deep eastern GoM. There is a clear ring separation from the LC body which, in both cases, is restricted west of the $86^{\circ} \mathrm{W}$ meridian; the satellite ADT maps present similar results. Both SSH and ADT maps show that Eddy Ekman was located between 24 to $26^{\circ} \mathrm{N}$ and 86 to $89^{\circ} \mathrm{W}$. Approximately 1 year later, Eddy Franklin was located over the same area, as captured by both model and satellite data. In addition, both fields show two distinct LCFEs to the north and south of the narrow area between the LCE and LC. These are cyclones that have contributed to the detachment process, following a sequence similar to the one analyzed by Le Hénaff et al. (2012a). This sequence incorporates $\mathrm{N}$ Group eddies (here represented by the LCFE that has migrated south from the NGoM region) and CB Group eddies (here represented by the second LCFE, which has migrated north from the Campeche Bank region); see Fig. 3. The evolution of these LCFEs during the two study periods is presented in Sect. 5.2.

\section{Results and discussion}

\subsection{Loop Current evolution in summers of 2009 and 2010}

Several detachments and reattachments took place before the final separation of Eddy Ekman and Eddy Franklin from the LC body during the summers of 2009 and 2010, respectively (Hamilton et al., 2011). Here, we focus on specific detachments during the two periods, when the surrounding LCFEs were apparent around and over the detachment area, in August 2009 (Eddy Ekman, Fig. 4a) and from midJune to mid-July 2010 (Eddy Franklin, Fig. 4b). During both events, a sequence of N Group and CB Group eddies was involved. Hamilton et al. (2011), based on altimeter-derived SSH data, identified three major detachment events during August 2009, before the final separation (see their Fig. 4). They show one event around August 10 and two more detachments over the last 10 days of August (Fig. 4). In agreement with their findings, we identified three successive detachment dates, based on the $17 \mathrm{~cm} \mathrm{SSH} \mathrm{contour} \mathrm{(Leben,}$ 2005) derived from the realistically forced, data assimilative GoM-HYCOM simulation, which preceded the final separation in September 2009. The detached LCE at the end of August is also presented in both simulated and satellite altimetry data in Fig. 3a; the LCE's eastern boundary is located around $87^{\circ} \mathrm{W}$, while the $\mathrm{LC}$ main body is restricted to east of $86^{\circ} \mathrm{W}$. 

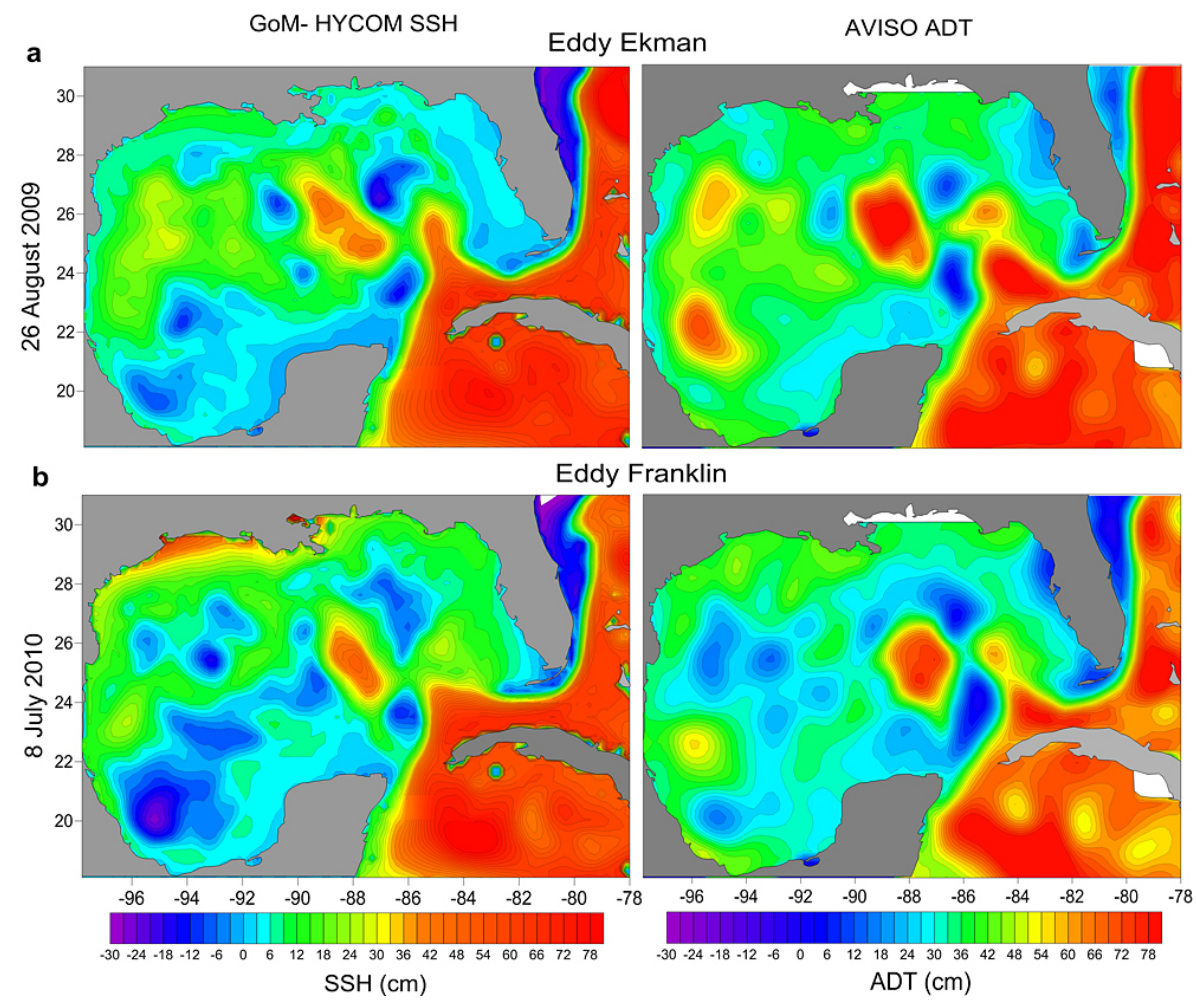

Figure 3. (left) Daily GoM-HYCOM Sea Surface Height (SSH, cm) for two characteristic LCE separation dates of (a) the Eddy Ekman event (26 August 2009) and (b) the Eddy Franklin event (8 July 2010), as well as (right) the respective weekly AVISO ADT (cm). The large cyclonic LCFEs between the anticyclonic LCEs and the main LC body are of N Group type (migrating southward from the northern GoM) and of CB Group type (migrating northward from the vicinity of the Campeche Bank).

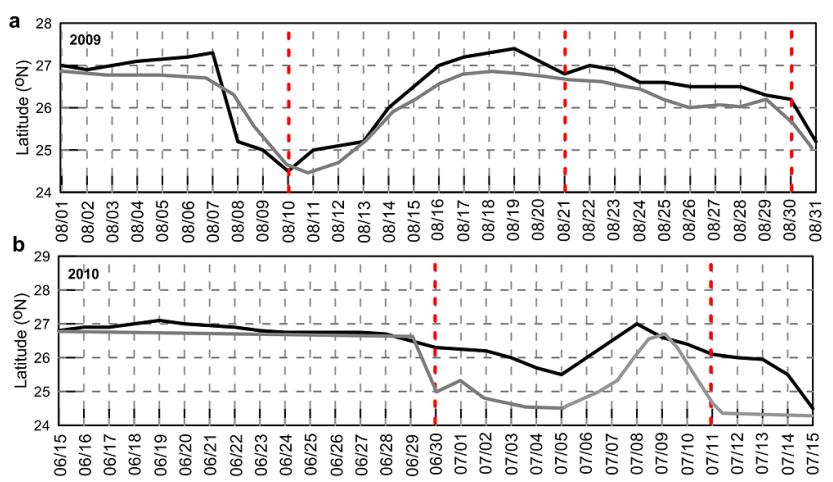

Figure 4. Latitude of furthest northward penetration of the LC, derived from the GoM-HYCOM $17 \mathrm{~cm}$ Sea Surface Height contour (black line) and adapted from Fig. 4 of Hamilton et al. (2011, grey line) during (a) August 2009 (Eddy Ekman event) and (b) June-July 2010 (Eddy Franklin event). Eddy detachment dates are indicated with vertical dashed red lines.

During the summer of 2010, two major detachment events took place in the beginning of July, which led to an extensive period of detachment between Eddy Franklin and the LC body. The GoM-HYCOM simulation agrees with observations from Hamilton et al. (2011), showing that the long detachment period began in early July, after two successive separations, lasted approximately 1 month and finally led to the reattachment of the LCE at the end of July 2010. On 15 July 2010, the LCE was completely detached from the $\mathrm{LC}$ body, located east of $86^{\circ} \mathrm{W}$ and around $24^{\circ} \mathrm{N}$.

\subsection{Tracks of frontal cyclones during Eddy Ekman and Eddy Franklin events}

We tracked the major LCFEs around the LC front from the model SSH, identified as local SSH minima (core of the cyclone), during the summers of 2009 and 2010. The evolution of the LCFEs and their influence on the detachment events during the two periods are investigated. We categorized and named the LCFEs based on their detection area. Moreover, eddies that formed after the merging of two or more preexisting cyclones from the N Group and CB Group constitute the M Group. The LCFEs' attributes are presented in Table 2.

Around mid-June 2009, an N Group cyclone was detected at the northern LC boundary (hereafter N1, Fig. 5a). N1 remained north of the LC until the end of June and moved southeastward, along the eastern LC front, during July. In the beginning of July and at the western side of the LC, a CB Group cyclone was detected (hereafter CB1) and propagated north, before it reached the LC "neck" on the first 


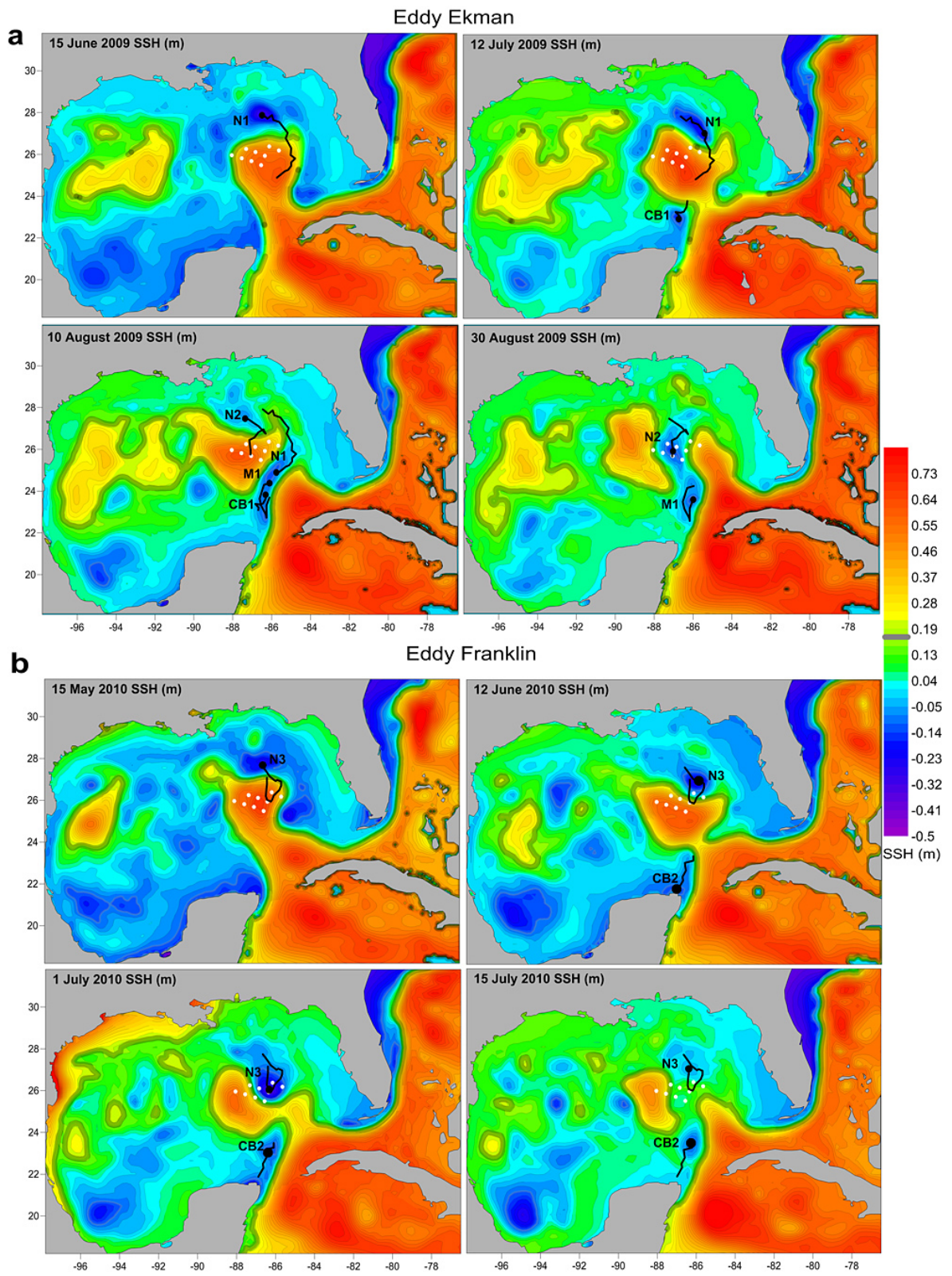

Figure 5. Sea Surface Height (SSH, m) distribution from GoM-HYCOM for four characteristic dates of the (a) Eddy Ekman and (b) Eddy Franklin case studies. The major LCFE tracks (when present on the four selected dates) are indicated with black lines. The black dots indicate the position of each cyclonic eddy on the specific panel date. The cyclonic LCFEs (total duration dates) are 15 June-10 August 2009 (N1), 12 July-10 August 2009 (CB1), 10 August-3 September 2009 (N2), and 10-30 August 2009 (M1) in the upper panels and 15 May -15 July 2010 (N3), and 12 June-15 July 2010 (CB2) in the lower panels (in Table 2). The moorings grid is also shown, marked with white dots. The $17 \mathrm{~cm} \mathrm{SSH}$ contour is indicated with a thick grey line on the color bar. (Note: the SSH color scale is different than in Fig. 3).

days of August. The merging of N1 and CB1 formed the cyclone named M1, during the LCE detachment event (around 10 August 2009). A second N Group cyclone (hereafter N2) was detected in the beginning of August and very quickly propagated southward. Based on the decreasing values in the related SSH signal, N2 intensified in the vicinity of the reattached but weak LC neck on 20 August 2009 and merged with the pre-existing M1 cyclone during the last days of August, inducing the final separation of the LCE; SSH at the N2 core was around $-0.10 \mathrm{~m}$ on 10 August and lower than $-0.20 \mathrm{~m}$ on 30 August (Fig. 5a). The merged cyclone remained over $87^{\circ} \mathrm{W}$ longitude (Table 2) during the final step of the shedding process that lasted approximately from 20 August until early September 2009. The resulting final 
Table 2. LCFE attributes during the Eddy Ekman and Eddy Franklin events. LCFEs are characterized as "N" when in the "N Group" (northern GoM eddies), "CB" when in the "CB Group" (Campeche Bank eddies), and "M" when in the "M Group" (Merged eddies).

\begin{tabular}{|c|c|c|c|c|c|}
\hline LCFE & Start lon/ & $\begin{array}{l}\text { Start date } \\
(\mathrm{mm} / \mathrm{dd} / \mathrm{yy})\end{array}$ & End lon/ & $\begin{array}{l}\text { at End date } \\
(\mathrm{mm} / \mathrm{dd} / \mathrm{yy})\end{array}$ & $\begin{array}{c}\text { Duration } \\
\text { (days) }\end{array}$ \\
\hline N1 & $\begin{array}{l}86.40^{\circ} \mathrm{W} \\
27.8^{\circ} \mathrm{N}\end{array}$ & $06 / 15 / 2009$ & $\begin{array}{l}85.7^{\circ} \mathrm{W} \\
24.95^{\circ} \mathrm{N}\end{array}$ & 08/10/2009 & 57 \\
\hline N2 & $\begin{array}{l}87.35^{\circ} \mathrm{W} \\
27.4^{\circ} \mathrm{N}\end{array}$ & 08/10/2009 & $\begin{array}{l}87.1^{\circ} \mathrm{W} \\
25.87^{\circ} \mathrm{N}\end{array}$ & 09/03/2009 & 25 \\
\hline N3 & $\begin{array}{l}86.62^{\circ} \mathrm{W} \\
27.65^{\circ} \mathrm{N}\end{array}$ & $05 / 15 / 2010$ & $\begin{array}{l}86.4^{\circ} \mathrm{W} \\
27.1^{\circ} \mathrm{N}\end{array}$ & $07 / 15 / 2010$ & 62 \\
\hline $\mathrm{CB} 1$ & $\begin{array}{l}86.45^{\circ} \mathrm{W} \\
22.9^{\circ} \mathrm{N}\end{array}$ & $07 / 12 / 2009$ & $\begin{array}{l}86.15^{\circ} \mathrm{W} \\
23.75^{\circ} \mathrm{N}\end{array}$ & 08/10/2009 & 30 \\
\hline CB2 & $\begin{array}{l}86.85^{\circ} \mathrm{W} \\
21.77^{\circ} \mathrm{N}\end{array}$ & $06 / 12 / 2010$ & $\begin{array}{l}86.32^{\circ} \mathrm{W} \\
23.45^{\circ} \mathrm{N}\end{array}$ & $07 / 15 / 2010$ & 34 \\
\hline M1 & $\begin{array}{l}85.95^{\circ} \mathrm{W} \\
24.35^{\circ} \mathrm{N}\end{array}$ & 08/10/2009 & $\begin{array}{l}85.9^{\circ} \mathrm{W} \\
23.7^{\circ} \mathrm{N}\end{array}$ & 08/30/2009 & 21 \\
\hline
\end{tabular}

separation of Eddy Ekman caused the LC body to retreat southward (not shown).

In 2010, Eddy Franklin began to form at the end of May, detached during the first days of June, and reattached and detached again in the middle and end of July, respectively. Finally, it separated completely from the LC by the end of September (Hamilton et al., 2011). Two major LCFEs surrounded the LC during the May-June period: N3 was detected initially along the northern LC boundary (N Group) in mid-May, while CB2 was detected in the vicinity of the Campeche Bank (CB Group) in mid-June (Fig. 5b). The intense and large N3 eddy was actually formed after the merging of three smaller pre-existing $\mathrm{N}$ Group cyclonic eddies (similar to observations by Walker et al., 2011). N3 lasted approximately 2 months (Table 2) and intruded southward at the end of June, contributing to the "necking-down" of Eddy Franklin in July. At the same time, CB2 was detected over the Campeche Bank in mid-June and slowly propagated northward, toward the LC body, until the end of the month. The necking-down of the LC started in the beginning of June, with several short-term detachments, followed by a longer detachment of Eddy Franklin in mid-July (in agreement with Hamilton et al., 2011).

\subsection{Structure and migration of northern gulf frontal cyclones}

We have presented LCFE migration from the northern GoM toward the south during both summer events. We analyze the vertical structure of $\mathrm{N}$ Group LCFEs, by employing the unique data set from the GoM moorings. As shown in Sect. 5.2, N Group cyclones propagated towards the south and intruded toward the neck of the LC, contributing to the detachment process during the summer periods of 2009 and 2010. Both N1 and N2 LCFEs covered a long distance from their formation site over the NGoM toward the ring detachment area during the summer of 2009 (Fig. 5a). N1 covered more than $3^{\circ}$ of latitude southward, from mid-June to early August. Then, N2 propagated rapidly towards the south during 20 days and ended up between the LC main body and the detached LCE at the end of August 2009. The N Group cyclone of the 2010 event (N3) lasted approximately 1.5 months, moving southward during the first few days and then northward until mid-July, when its intensity declined until it was finally eroded.

The unique set of measurements from the moorings over the US-Mexico EEZ boundary (Sect. 3.2) mainly detected the southward migration of $\mathrm{N} 2$ and $\mathrm{N} 3$ eddies, while the $\mathrm{N} 1$ cyclone propagated around and east of the mooring grid (Fig. 5a). However, its southward track was partially recorded by the most eastern moorings. The in situ temperature measurements at several depths down the water column from surface to bottom allow the detailed and precise description of the vertical structure of the $\mathrm{N}$ Group cyclones under study. We use in situ measurements to describe the cyclone deep vertical structure, while the use of model results is better suited at the surface, where the cyclone's exact position can be accurately retrieved, as the model assimilates near-surface fields. Mesoscale eddies are associated with a substantial vertical movement of water masses; cyclonic LCFEs are associated with the shoaling of isotherms at the core of the eddy. The presence of cyclonic eddies in the GoM may thus form temperature lows at all depths, with values lower than those associated with the LC removal away from the mooring area.

By mid-July 2009, the N1 eddy was blocked between the LC front and the northeastern corner of the GoM shelf break, formed where the west Florida shelf and the NGoM shelf meet. N1 propagated around and east of the moorings until it reached the neck of the LC in early August 2009 (Fig. 5a). The track of the LCFE was partially recorded by the most eastern $\mathrm{C} 1$ and $\mathrm{C} 2$ moorings, located close to the west Florida shelf (Fig. 1) in mid-July, revealing temperature drops, especially at depths shallower that $750 \mathrm{~m}$ (Fig. 6). The core of the cyclone was outside the mooring grid during the entire N1 period, and, therefore, it is not possible to draw clear conclusions about the vertical structure and coherence of this particular LCFE. However, the most eastern C2 mooring measured the lowest temperature values of the entire summer during mid-July at both upper $(250 \mathrm{~m})$ and lower $(1500 \mathrm{~m})$ sensors, capturing the passage of the cyclone (Fig. 6b). The drop in temperature is almost $10^{\circ} \mathrm{C}$ in the upper sensor. The upper part of $\mathrm{N} 1$ passed closer to $\mathrm{C} 2$, recording a temperature reduction larger than in $\mathrm{C} 1$. The drop in temperature measured by the 750 and $900 \mathrm{~m}$ sensors $\left(\sim 3^{\circ} \mathrm{C}\right)$ by both $\mathrm{C} 1$ and $\mathrm{C} 2$ moorings also indicates the passage of $\mathrm{N} 1$ over the area. The N1 surface signal is weaker at the most southeastern A4 mooring in the beginning of August (Fig. 8b), as the eddy moved more to the south (Fig. 5a). As expected, the $\mathrm{N} 1$ signal is absent from the $\mathrm{A} 3$ measurements 


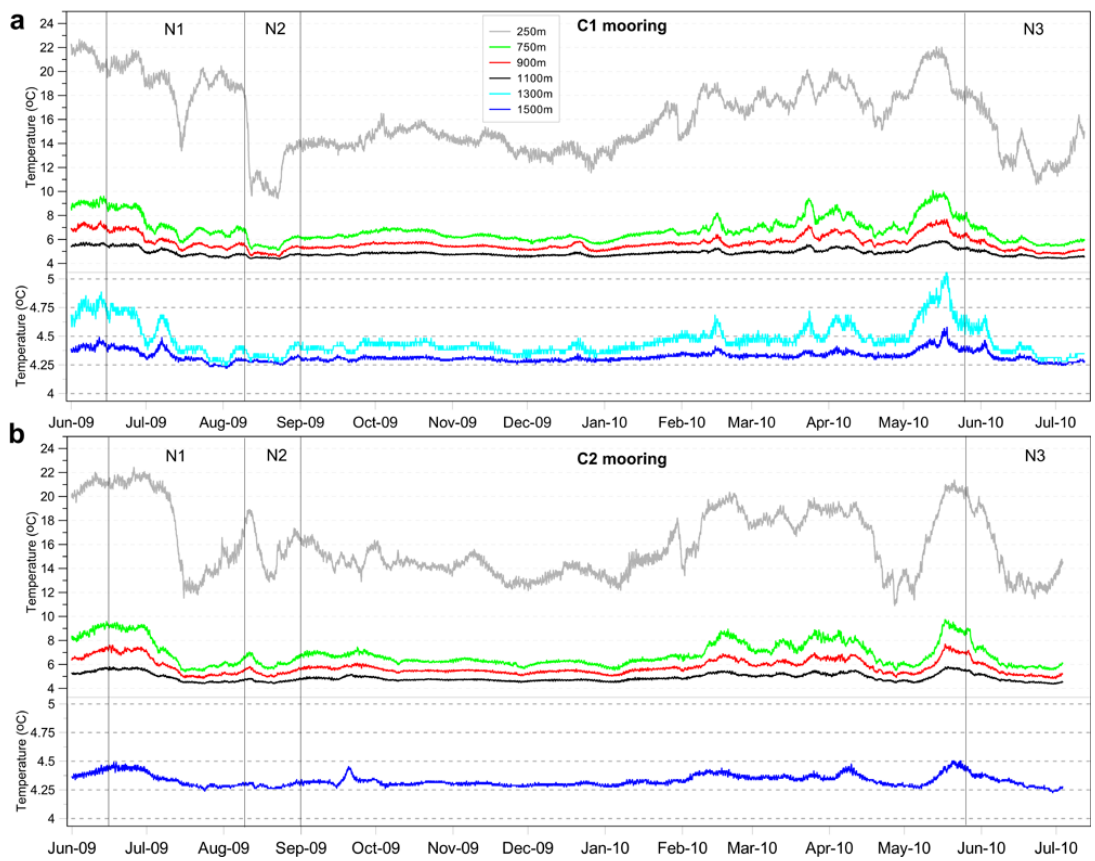

Figure 6. Sea temperature $\left({ }^{\circ} \mathrm{C}\right)$ temporal evolution at several depths $(250,750,900,1100,1300$, and $1500 \mathrm{~m})$ from (a) $\mathrm{C} 1$ and (b) $\mathrm{C} 2$ moorings (Fig. 1) from June 2009 to mid-July 2010. The 1300 and $1500 \mathrm{~m}$ time series are plotted with a different $y$ axis for clarity reasons. The LCFE N1, N2, and N3 periods are indicated with black solid vertical lines.

(Fig. 8a). All layers at A3 were inside the LC extension, with high temperature values during the entire month.

As presented in Sect. 5.2, the N2 eddy intruded in the central area of the mooring grid. It was initially well formed over the northern Gulf shelf slope and approached the deep GoM at the northern edge of the LC extension (Fig. 5a). At first, the eddy approached the $\mathrm{C} 1$ mooring, lowering the temperature levels at all depths in mid- and late August 2009 (Fig. 6a), in agreement with the simulated surface SSH fields presented in Sect. 5.2 (Fig. 5a). The vertical coherence of the eddy is also apparent at the B3 mooring in late August and early September, when a temperature low was measured at depths greater than $1300 \mathrm{~m}$ (Fig. 7b). The southward propagation of the eddy was also detected by the most southern A4 mooring at the end of August and in the beginning of September (Fig. 8b), when cooler waters occurred in comparison with the rest of the time series at all depths $(250-1500 \mathrm{~m})$, indicating that the temperature drops were due to a cyclone, in addition to the LC being away from the moorings. This is reflected by the SSH distribution, presented in Fig. 5a, where the surface signal of $\mathrm{N} 2$ is clearly seen over the central moorings after its southward migration. This LCFE finally reached the A3 mooring in early September (Fig. 8a), when it lowered the temperature at all depths as well, showing the lowest values of the entire time series. The most western A1 and A2 moorings also partially captured the upper layer's temperature decrease due to the cyclone intrusion (not shown). Then, the vertically coherent $\mathrm{N} 2$ cyclone moved southward and merged with CB1, leading to the Eddy Ekman detachment (Fig. 5a).

One year later, during the Eddy Franklin shedding period, the N3 LCFE southward propagation was also accompanied by a temperature decrease. This was especially evident at the most northeastern $\mathrm{C} 1$ in mid-June 2010 (Fig. 6a), the most eastern $\mathrm{C} 2$ in late June (Fig. 6b) and the most southern A4 in early July (Fig. 8b), indicating the LCFE southward propagation (see also Fig. 5b). The more centrally located B2 and B3 moorings captured the eddy track, showing significantly large drops at all depths. Similar to the N2 period, C1 and $\mathrm{C} 2$ moorings showed minimal temperature at all depths during the N3 period, supporting the presence of a vertically coherent cyclone. Temperature decrease also occurred at A3 mooring during the same period. However, the drops were not larger than the respective general low levels during the rest of the year, especially at the upper $(250 \mathrm{~m})$ and deeper $(>1300 \mathrm{~m})$ parts. These variations can thus be due to the presence or absence of the LC or LCE at this specific location, rather than the signature of an LCFE. The signature of N3 is not seen at A1 and A2 (not shown), as the eddy does not reach these locations. After its participation in the LCE detachment process, N3 moved northward, outside the array, allowing the temperature to increase at $\mathrm{C} 1, \mathrm{C} 2, \mathrm{~B} 2, \mathrm{~A} 3$, and A4 moorings by mid-July 2010 . 


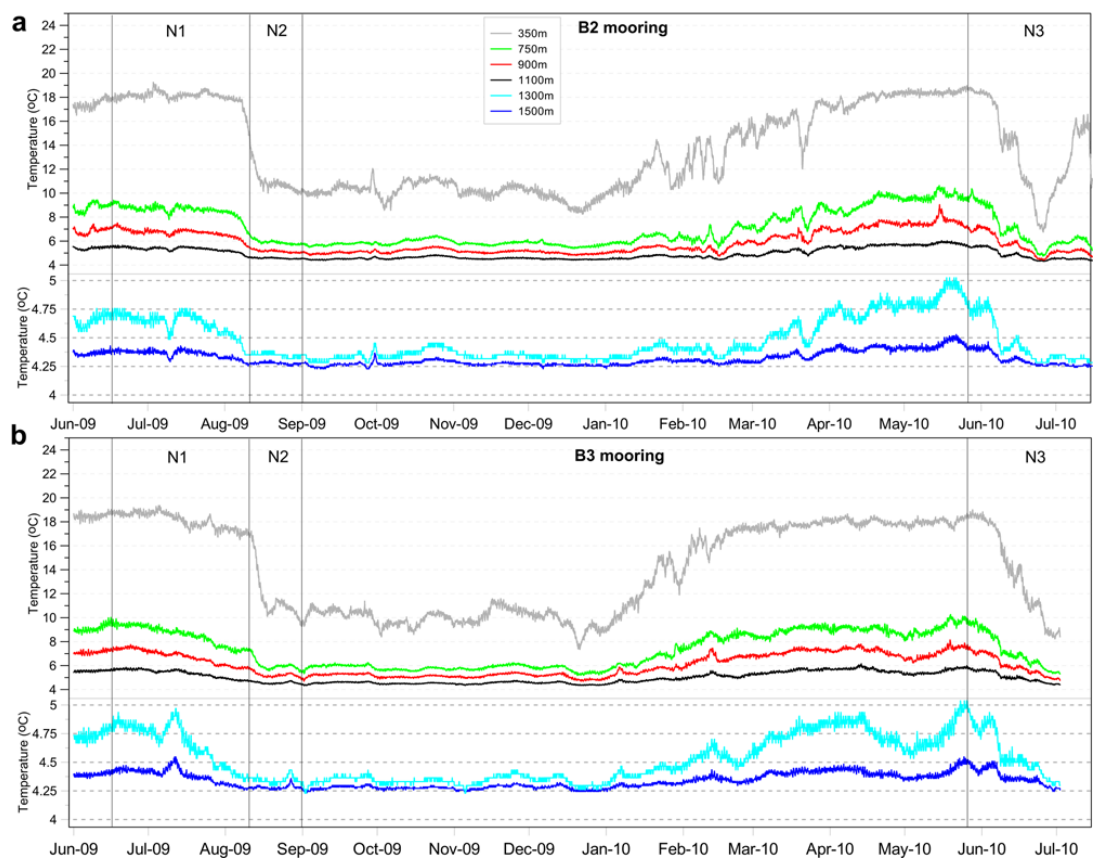

Figure 7. Sea temperature $\left({ }^{\circ} \mathrm{C}\right)$ temporal evolution at several depths $(350,750,900,1100,1300$, and $1500 \mathrm{~m})$ from (a) B2 and (b) B3 moorings (Fig. 1) from June 2009 to mid-July 2010. The 1300 and $1500 \mathrm{~m}$ time series are plotted with a different $y$ axis for clarity reasons. The LCFE N1, N2, and N3 periods are indicated with black solid vertical lines.
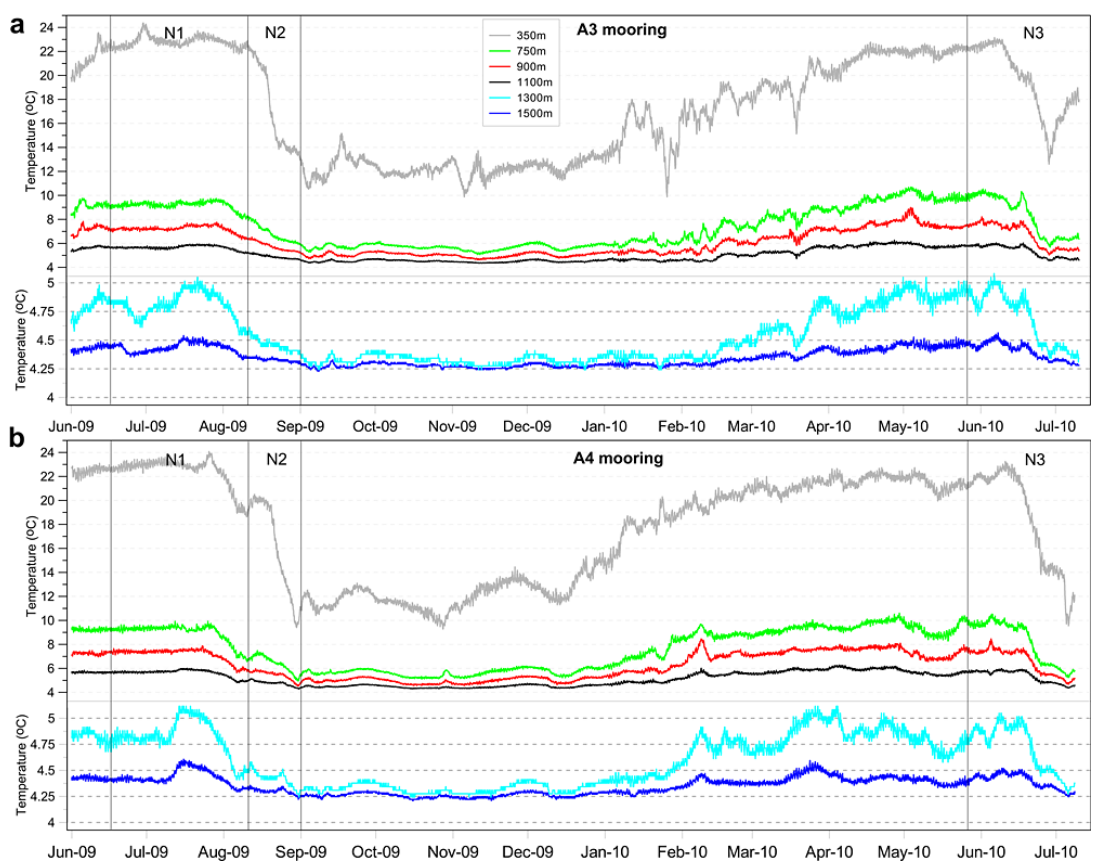

Figure 8. Sea temperature $\left({ }^{\circ} \mathrm{C}\right)$ temporal evolution at several depths $(350,750,900,1100,1300$, and $1500 \mathrm{~m})$ from (a) A3 and (b) A4 moorings (Fig. 1) from June 2009 to mid-July 2010. The 1300 and $1500 \mathrm{~m}$ time series are plotted with a different $y$ axis for clarity reasons. The LCFE N1, N2, and N3 periods are indicated with black solid vertical lines. 

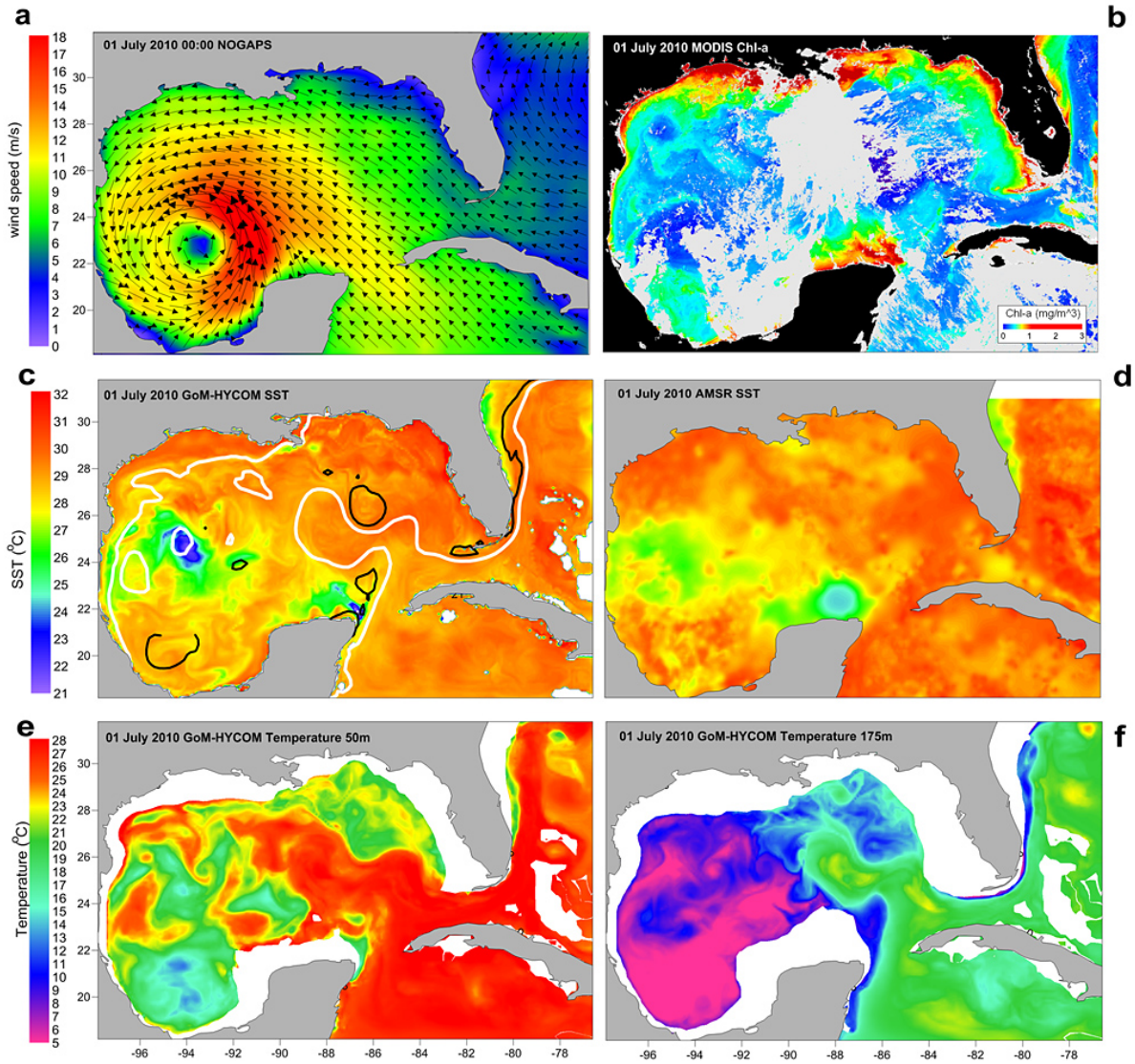

Figure 9. Horizontal distribution over the GoM-HYCOM region on 1 July 2010 of (a) wind stress (vectors, $\mathrm{m}^{2} \mathrm{~s}^{-1}$ ) and wind speed magnitude (colors, $\mathrm{m} \mathrm{s}^{-1}$ ) from the NOGAPS model, (b) satellite MODIS chl $a\left(\mathrm{mg} \mathrm{m}^{-3}\right)$, (c) model Sea Surface Temperature (SST, ${ }^{\circ} \mathrm{C}$ ) with superimposed model Sea Surface Height (SSH) contours (white lines: $17 \mathrm{~cm}$; black lines: $-8 \mathrm{~cm}$ ), (d) satellite AMSR SST $\left({ }^{\circ} \mathrm{C}\right.$ ), (e) model temperature $\left({ }^{\circ} \mathrm{C}\right)$ at $50 \mathrm{~m}$, and (f) model temperature $\left({ }^{\circ} \mathrm{C}\right)$ at $175 \mathrm{~m}$.

\subsection{Campeche Bank Loop Current Frontal Eddy evolution and growth}

We investigate if shelf processes along the Campeche Bank may contribute to adjacent CB Group LCFE evolution. In particular, an event of export of shelf waters from the Campeche Bank to the CB2 LCFE during an upwelling event is analyzed. As shown in Sect. 5.2, CB2 was formed over the Campeche Bank, close to the Yucatan Peninsula; propagated northward, and intruded toward the LC neck, contributing to the detachment of Eddy Franklin in July 2010. An important environmental condition during the formation, intensification, and northward propagation of the CB2 eddy was the upwelling event on the Campeche Bank due to the passage of Hurricane Alex over the GoM region in June-July 2010 (Stewart and Cangialosi, 2012). Possible implications for $\mathrm{CB} 2$ evolution are examined here.

\subsubsection{Upwelling event over the Campeche Bank}

The coastal and shelf waters over the Campeche Bank are frequently subject to upwelling-favorable winds, due to the prevailing easterlies over this area (Zavala-Hidalgo et al., 2006). A strong upwelling event took place just before the detachment of Eddy Franklin in early July 2010, associated with the passage of Hurricane Alex, which developed in late June 2010 as the first tropical cyclone in the 2010 Atlantic hurricane season. The low-pressure system was formed over the western Caribbean Sea on 25 June 2010 and propagated toward the western GoM until 2 July 2010, following a northwestward path over the Campeche Bank (Fig. 9a). Here we concentrate on the impact of the associated strong southeasterly winds that followed the storm path and produced upwelling-favorable conditions over the Campeche Bank and along the Yucatan Peninsula. As a result, significant masses of deeper nutrient-rich and cold waters were upwelled along the northern tip of the Yucatan Peninsula, as evident from MODIS (Moderate-Resolution Imaging Spectroradiometer) satellite chl $a$ (Fig. 9b) and SST (Fig. 9d) data on 1 July 2010. The local transport, associated with the upwelling, advected surface water masses to the north and allowed the nutrientrich waters to reach the upper layers and increase the primary production, evidenced by higher chl $a$ concentrations over 


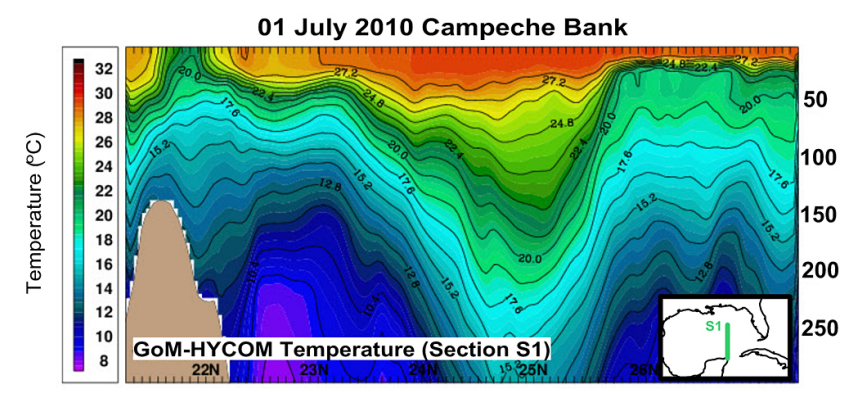

Figure 10. Campeche Bank temperature $\left({ }^{\circ} \mathrm{C}\right)$ along the $\mathrm{S} 1$ vertical section (GoM insert: green line) on 1 July 2010.

the Campeche Bank. Such phenomena are locally frequent (Martinez-López and Zavala-Hidalgo, 2009).

The upwelling event was successfully represented in the GoM-HYCOM simulation. Surface waters of quite low temperature $\left(<25^{\circ} \mathrm{C}\right)$ were estimated over the Campeche Bank (as compared to $\sim 30^{\circ} \mathrm{C}$ ambient waters) during the passage of Hurricane Alex (Fig. 9c), in agreement with the AMSR SST fields (Fig. 9d). The strongest impact of the upwelling was on the eastern part of the Campeche Bank $\left(\sim 87^{\circ} \mathrm{W}\right)$, where the lowest near-surface temperatures of the entire GoM were both measured and simulated on 1 July 2010. Low temperatures were also simulated at $50 \mathrm{~m}$ (Fig. 9e) and $175 \mathrm{~m}$ (Fig. 9f), showing the presence of colder waters from the deeper layers along the eastern Campeche Bank slope. A north-south vertical cross section of temperature (Fig. 10) gives additional details. Low-temperature water masses $\left(\sim 10^{\circ} \mathrm{C}\right)$ were detected in the intermediate layers $(\sim 175 \mathrm{~m})$ at $24^{\circ} \mathrm{N}$ latitude. Low temperatures $\left(17^{\circ} \mathrm{C}\right)$ were also found closer to the surface $(\sim 50 \mathrm{~m})$ at $22^{\circ} \mathrm{N}$ latitude, above a shallow area $(150 \mathrm{~m})$ over the Campeche Bank. In contrast, the upper layers of the LC pattern $\left(23-26^{\circ} \mathrm{N}\right)$ carry significantly warmer water masses $\left(\sim 30^{\circ} \mathrm{C}\right)$; the warm surface waters spread southward, reaching the continental shelf slope area.

As CB2 eventually involved in the shedding of Eddy Franklin by mid-July, we seek to further examine the connection between the winds that induced upwelling over the Campeche Bank and the export of shelf waters across the shelf break slope that may lead to the growth of CB Group cyclonic eddies. We note that these cyclones are LCFEs, which generally travel around the LC. They experience intensification when they migrate further north along the LC edge (Oey, 2008; Le Hénaff et al., 2012a). Here we examine an additional process that may enhance the growth of $\mathrm{CB}$ Group eddies, with implications for promoting their role on LCE formation, detachment, and separation.

\subsubsection{Contribution of slope processes to Campeche Bank cyclone evolution and growth}

The proximity of the Campeche Bank slope to the LC front and associated LCFEs provides the unique opportunity to examine if shelf processes may interact with and impact the deep basin mesoscale variability. We focus on the potential role of cold shelf waters resulting from wind-driven upwelling in the evolution of CB2. We employ an analysis of the associated Potential Vorticity (PV) field, based on the GoM-HYCOM simulation. Since in geostrophic balance an eddy is associated with a local extremum of PV (Ertel, 1942), such a PV analysis is suited for investigating the evolution of the CB2 eddy. In addition, PV analysis has been used in the past to investigate upwelling-related shelf processes, in simplified model studies (e.g., Rossi et al., 2010). Appendix A presents the detailed description of our PV analysis method, which leads us to look for a PV anomaly in the water column, associated with CB2. We derive three simplified model layers (based on density levels): the upper layer extends from 0 to 50 or $100 \mathrm{~m}$ in the study area; the intermediate layer, where the high-PV core associated with CB2 is located, is about $100 \mathrm{~m}$ thick inside the eddy; and the deep layer below extends to the bottom. We now present results based on the analysis of the PV field in these simplified layers.

Figures 11 and 12 show snapshots of the PV in the simplified layers 1 and 2, respectively. They show that filaments exporting high PV from the Campeche Bank to the GoM interior are often seen in the upper layer (Fig. 11), for example on 31 May or 13 June, but these filaments do not aggregate into a coherent structure. On the other hand we see a core of high PV forming and growing along the Campeche Bank slope in the intermediate layer 2 (Fig. 12). There is no such core in early May, but episodes of export of high PV from the eastern Campeche Bank are observed between mid- and late May, for example on 18 and 26 May. These lead to the formation of a core of high PV on the continental shelf slope, located around $\left(86.5^{\circ} \mathrm{W}, 23.5^{\circ} \mathrm{N}\right)$ on 31 May. This core of high PV keeps growing by aggregating high PV not only from the Caribbean, flowing into the GoM along the Campeche Bank, but also from the Campeche Bank itself, in intense episodes of export, such as on 13 and 30 June. During June, the area covered by the eddy increases, and the eddy extends northeastward. Then, between late June and mid-July, the core of high PV separates from the Campeche Bank, forming a closed, circular pattern, reflecting an isolated cyclone. Between early and mid-July, the core of high PV moves northward, toward the GoM interior.

This high-PV core is the signature of $\mathrm{CB} 2$, which forms and grows along the Campeche Bank. The sequence in Fig. 12 illustrates the importance of episodes of export of high PV from the Campeche Bank to the shelf slope, together with the advection of high PV from the Caribbean, in the formation and growth of CB2. Once well formed and detached from the Campeche Bank, CB2 migrates north, before later 

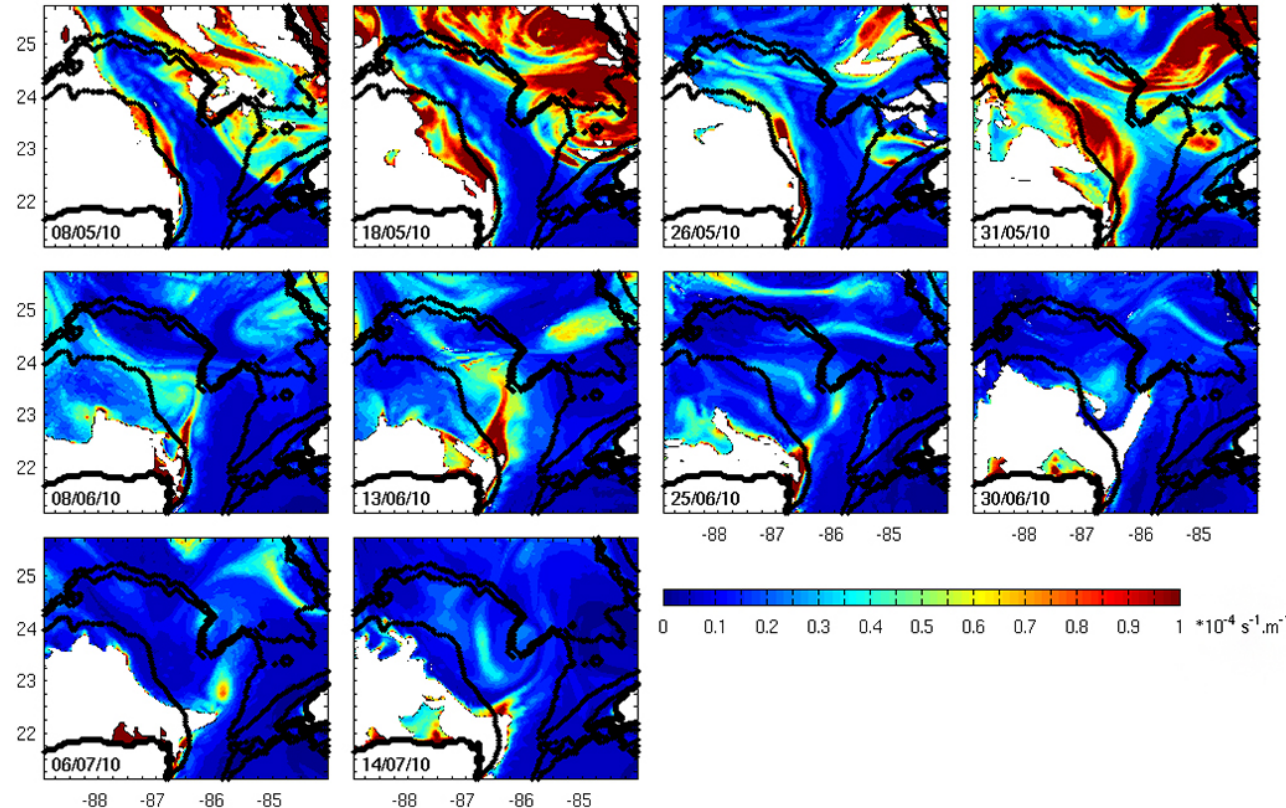

Figure 11. Snapshots of PV in layer 1 (of three-layer simplified analysis of model outputs), on 8, 18, 26, and 31 May; 8, 13, 25, and 30 June; 6 and 14 July 2010. Thick black lines are the 200, 2000, and $3000 \mathrm{~m}$ isobaths. White patches are areas where layer 1 vanishes, which happens when there is no water of density in the range defining the simplified isopycnal layer 1 (see Appendix A).
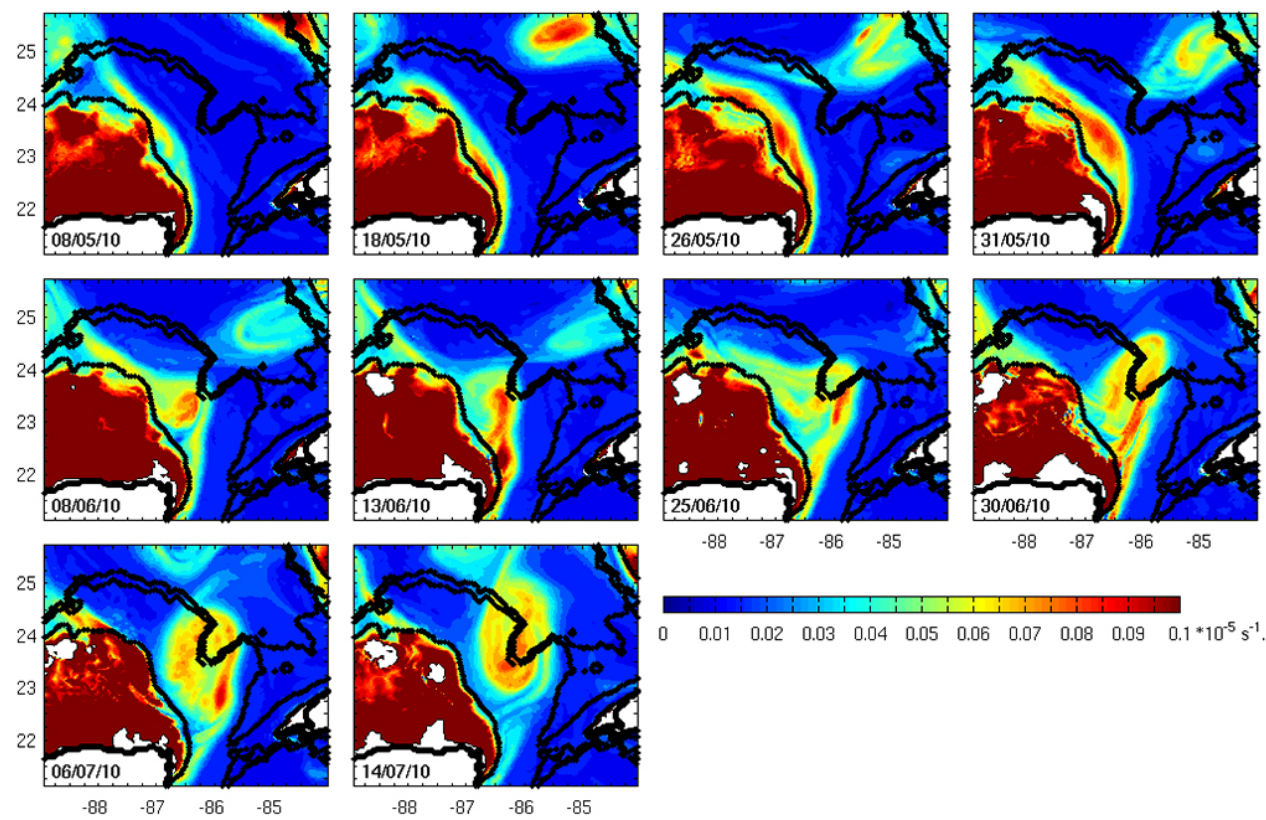

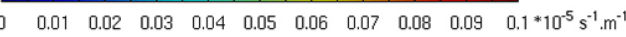

Figure 12. Snapshots of PV in layer 2 (of three-layer simplified analysis of model outputs), on 8, 18, 26, and 31 May; 8, 13, 25, and 30 June; 6 and 14 July 2010. Thick black lines are the 200, 2000, and $3000 \mathrm{~m}$ isobaths. White patches are areas where layer 2 vanishes, which happens when there is no water of density in the range defining the simplified isopycnal layer 2 (see Appendix A).

interacting with the northern $\mathrm{N} 3$ eddy, which leads to the LCE detachment (see discussion based on the Fig. 5b SSHderived sequence in Sect. 5.2). From both Figs. 11 and 12, it is evident that the PV anomaly associated with CB2 is located in intermediate layer 2, and we will focus on the evolu- tion of PV within that layer. We now examine the role of the wind-driven upwelling in this LCFE growth process.

Figure 13 shows the total layer 2 offshore transport, as well as the total layer 2 positive PV transport, from the Campeche Bank to the GoM interior, calculated along the slope, taken 

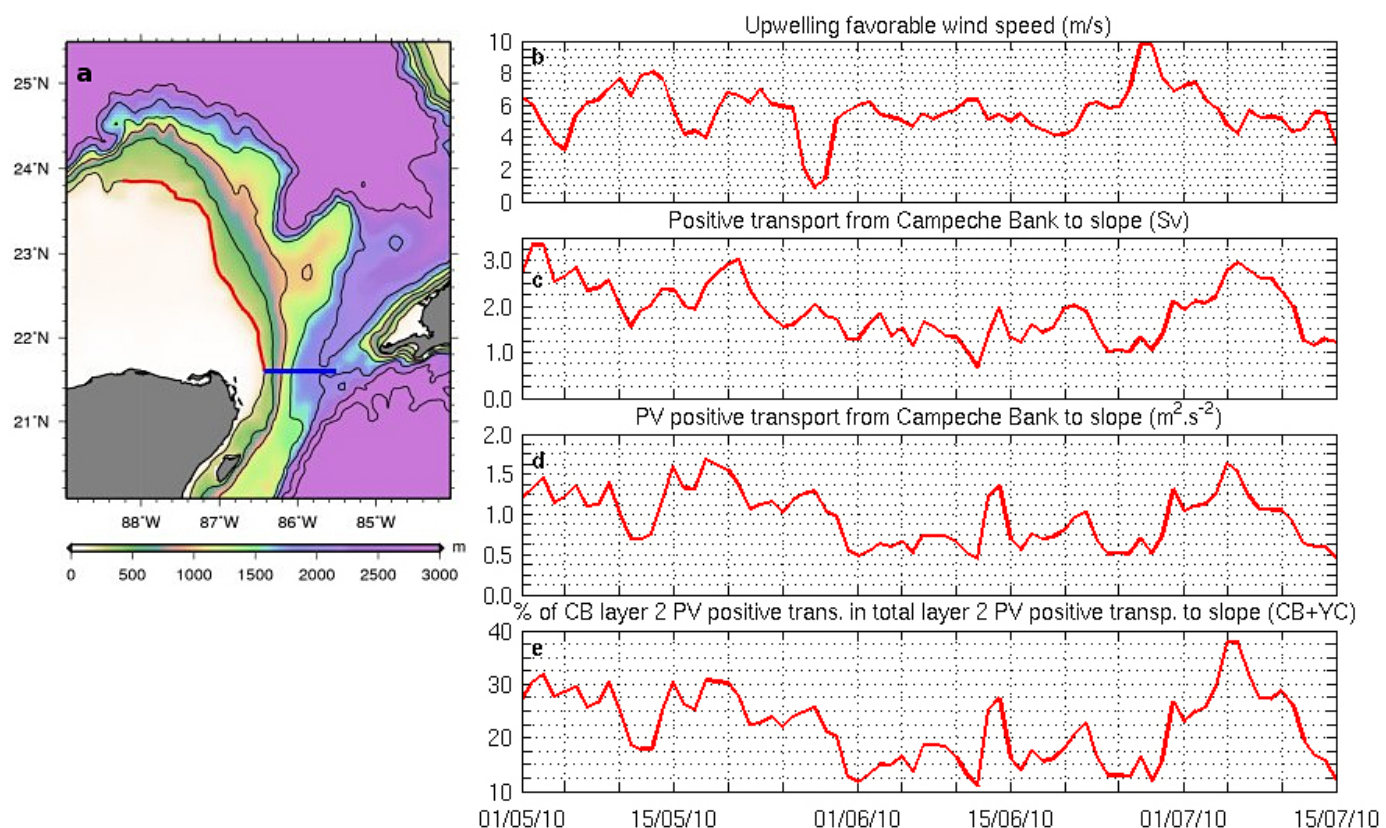

Figure 13. (a) Topography detail around Campeche Bank (CB), marking the slope (along the $200 \mathrm{~m}$ isobath, from 21.6 to $23.9^{\circ} \mathrm{N}$ : red line) and the Yucatan Channel (YC; extended from the CB slope to $85.5^{\circ} \mathrm{W}$ : blue line). Time series of (b) magnitude of along-shore wind speed $\left(\mathrm{m} \mathrm{s}^{-1}\right)$ at the northern coast of the Yucatan Peninsula, (c) positive part of the transport (Sv) exported through CB in simplified layer 2; (d) same as (c); but for PV positive (offshore) transport $\left(\mathrm{m}^{2} \mathrm{~s}^{-2}\right)$; and (e) ratio (\%) of the PV positive transport in layer 2 from the $\mathrm{CB}$ to the GoM interior, over the combined positive transport from the CB and YC sections. (b-e) Vertical lines are on the 1st, 5th, 10th, 15th, 20th, and 25th day of each month.

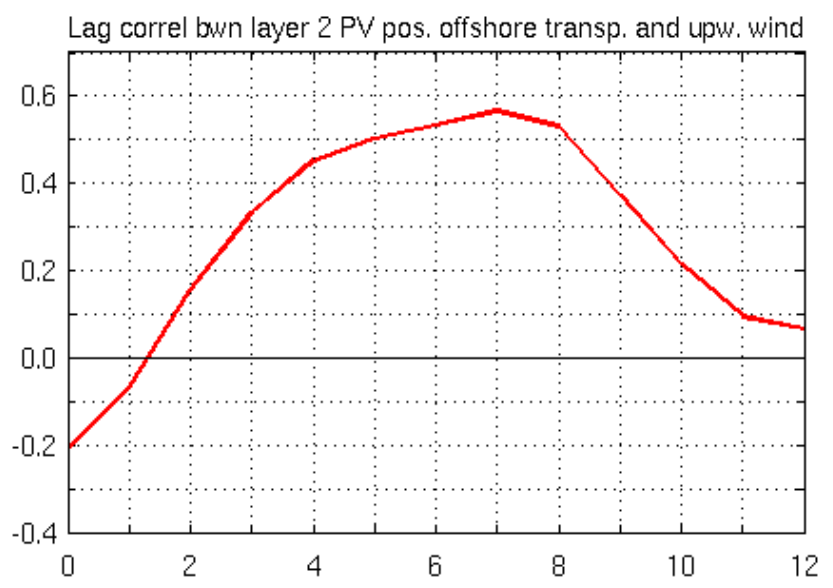

Figure 14. Lag correlation between the magnitude of along-shore wind for the northern coast of the Yucatan Peninsula and the PV positive (offshore) transport from the Campeche Bank (CB section, Fig. 14a) to the GoM interior in layer 2 (of three-layer simplified analysis of full model outputs).

at the $200 \mathrm{~m}$ isobath (red line in Fig. 13a). The positive, offshore transport tends to respond to the easterly winds (upwelling favorable for the northern coast of the Yucatan Peninsula), with a time lag (Fig. 13b and c). Based on the direction of these westward winds, an induced Ekman transport is ex- pected to the north, which should lead to an export of waters from the Campeche Bank toward the GoM interior. Indeed, peaks of layer 2 offshore transport tend to take place a few days after easterly wind bursts. This is the case in early July, following the passage of Hurricane Alex in late June. A previous peak of upwelling winds around 13 May also led to a peak of positive transport a few days later (21 May). Then, the evolution of the offshore advection of PV by this positive transport (Fig. 13d) is driven by the changes in offshore transport, modulated by changes in the PV values. Figure 13e provides a comparison between the PV transport exported through the Campeche Bank slope (red line in Fig. 13a) and the total PV transport, which includes the contribution from the Caribbean through the Yucatan Channel (blue line in Fig. 13a). At times following upwelling-favorable winds, the contribution of the Campeche Bank to the layer $2 \mathrm{PV}$ core can reach up to $38 \%$ of the total PV transport. This PV flux has the potential to feed the CB2 eddy core, although during that period (May-June 2010) the PV flux was mostly due to import from the Caribbean.

Figure 14 illustrates the positive lagged correlation between the along-shore winds and the offshore PV transport from the Campeche Bank. The PV transport in layer 2 is positively correlated with the upwelling-favorable winds after the wind peaks, and it reaches a correlation of 0.55 at 7-day lag. The correlation observed in the time series and illustrated in 

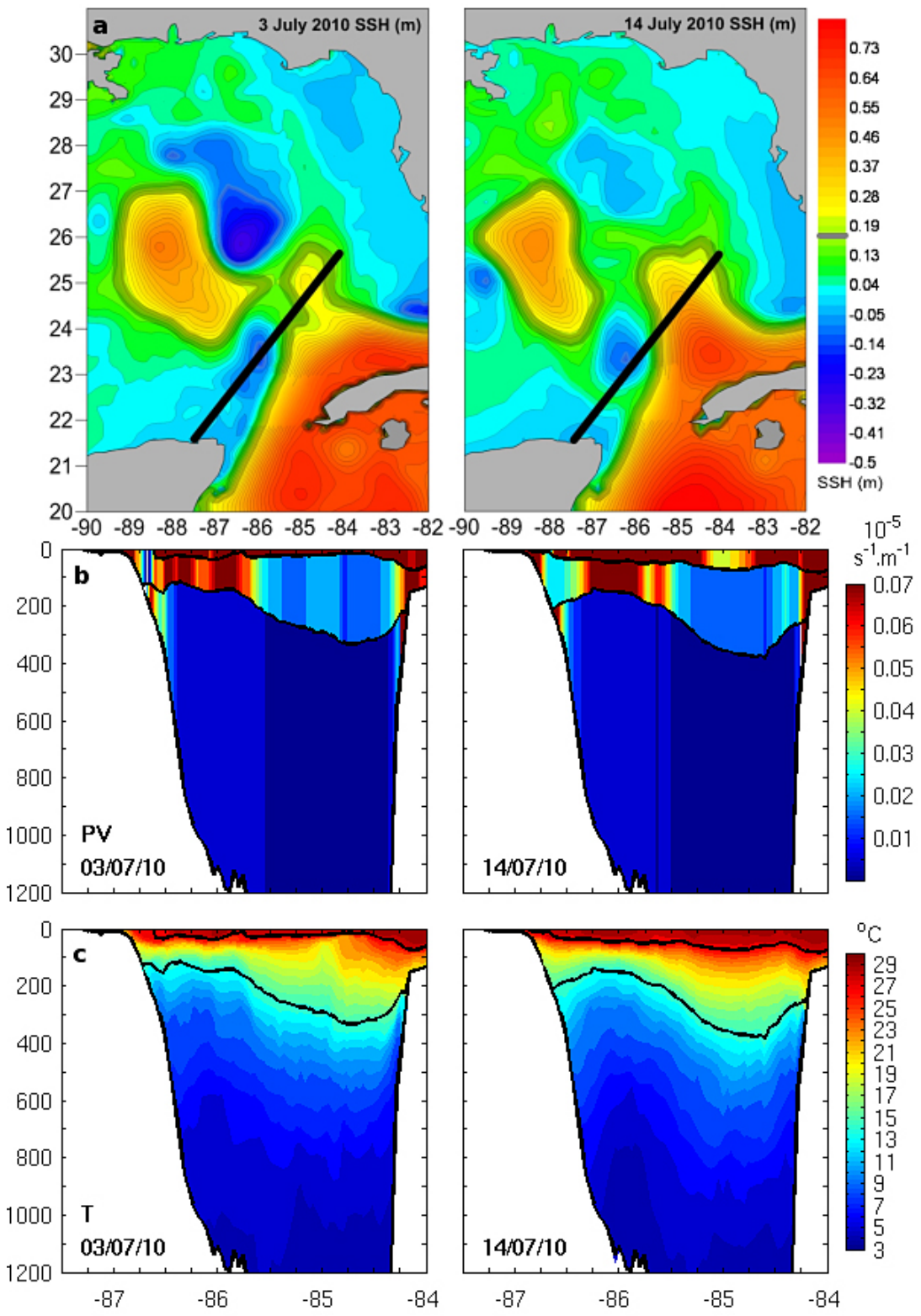

Figure 15. (a) Snapshots of simulated Sea Surface Height (SSH, m) and the section (black line) where the vertical distribution of (b) Potential Vorticity $\left(\mathrm{PV} \mathrm{m}^{-1} \mathrm{~s}^{-1}\right)$ and (c) temperature $\left({ }^{\circ} \mathrm{C}\right)$ are presented, for 3 July 2010 (left) and 14 July 2010 (right). PV is given in the three layers of the simplified analysis of model outputs (black lines indicate layer thickness), while temperature is given over the full range of model layers (same black lines added for reference).

Fig. 14 shows that upwelling-favorable winds promote the transport of high PV from the Campeche Bank to the GoM interior, where it participates in the growth of the core of high PV associated with CB2.

The evolution of CB2 from the shelf slope to the offshore GoM is presented in a cross-slope vertical section along the direction of the CB2 eddy pathway (Fig. 15), for two snapshots (3 and 14 July 2010). The corresponding model SSH maps illustrate the presence of the eddy first along the $\mathrm{CB}$ slope on 3 July and then offshore to the north on 14 July
(Fig. 15a), where it contributes to the Eddy Franklin detachment. The vertical sections of PV illustrate this migration by the displacement of the high-PV patch in layer 2, associated with the eddy, from along the shelf slope to the GoM interior between the two dates (Fig. 15b). These high PV values in layer 2 are associated with the lower-layer thickness, due to the shoaling of cold waters from depth (Fig. 15c). Along the CB slope, on 3 July, this shoaling is typical of the upwelling signature. It is maintained when the eddy migrates offshore, as seen on 14 July. Figure 15 also shows how layer 2 is thin- 
ner over the $\mathrm{CB}$ than in the deeper GoM, which, based on the definition of PV (Eq. A1), favors its role as a reservoir of high PV. Episodes of upwelling-favorable winds lead to the offshore export of these high-PV waters.

Although the contribution of the positive PV flux from Campeche Bank to the growth of the LCFE is not dominant, it is not negligible. This analysis offers novel evidence on the contribution of upwelling-favorable winds over the Campeche Bank to the growth of adjacent LCFEs, in addition to other processes contributing to their cyclonic vorticity. It also shows an interesting aspect of slope processes, where the impact is felt far beyond the shelf break, on the mesoscale variability of the deep basin interior. Although we examined an event in the wake of a hurricane, periods of strong and sustained upwelling-favorable winds are locally common, suggesting that we have identified a process that merits further study, during several episodes of similar conditions.

\section{Conclusions}

A numerical simulation with the regional GoM-HYCOM model (realistic forcing and data assimilation), in tandem with in situ measurements and satellite altimetry and temperature data, have provided a comprehensive description of changes in the LC system during two summer periods. In particular, changes associated with the position and evolution of cyclonic LCFEs during two sequences of anticyclonic LCE shedding were studied. These LCFEs were from two characteristic GoM groups: N Group (migrating southward from the northern GoM) and CB Group (migrating northward from the vicinity of the Campeche Bank). The data have revealed unprecedented details on the three-dimensional changes of water properties marked by LC evolution, where LCFEs and LCEs play a dominant role. The model results have corroborated findings from the observations and have allowed for the additional study of eddy history and transformations, under the complex GoM circulation forcing mechanisms and topographic controls. Advection, growth, and intensification of the LCFEs are notable factors favoring their involvement in the anticyclonic ring shedding process.
Cyclonic LCFEs were involved in the detachment events during Eddy Ekman and Eddy Franklin, shedding from the main LC body during the summers of 2009 and 2010, respectively. We have identified two N Group LCFEs during the Ekman period and one during the Franklin period as the main ones contributing to LCE detachment from the north, and we studied their sub-surface characteristics based on new in situ temperature data. All N Group LCFEs that participated in the two detachment events were vertically coherent to at least $1500 \mathrm{~m}$, as shown by in situ measurements that captured their southward propagation. We showed that the LCE detachment was aided by the combination of $\mathrm{N}$ Group and CB Group LCFE activity.

The indirect effect of the winds on the growth of the Campeche Bank LCFEs was found to be related to the Eddy Franklin detachment process. Strong upwelling-favorable winds, which are locally common but can be particularly intensified during tropical storms and hurricanes, may bring colder deep waters over the Campeche Bank upper layers. We have shown that such upwelling is the source for the transfer of high PV from the Campeche Bank to the continental slope, which was associated with the formation and growth of the CB Group LCFE under study. This enlarged LCFE moved northward, toward the LC extension area, contributing to the narrowing of the LC neck and, together with $\mathrm{N}$ Group LCFEs, to the detachment of the anticyclonic ring. We deduce that such a sequence could be typical during episodes of strong and sustained upwelling-favorable winds. Our findings suggest that the study of several such periods should be pursued.

The study of the 2009 and 2010 LCE events has identified the major cyclonic eddies that participated in the detachment processes; revealed the sub-surface characteristics of some of them; and demonstrated an indirect role of winds in the detachment process, contributing to the growth of LCFEs through their influence on slope exchanges. 


\section{Appendix A: Potential vorticity analysis}

In geostrophic balance, an eddy is associated with a local extreme of Potential Vorticity (Ertel, 1942). An eddy is associated with a PV anomaly that can be located in a specific part of the water column, but which can influence the whole eddy (Herbette et al., 2003; Meunier et al., 2010). We have undertaken a PV analysis, seeking such a PV anomaly signature in the water column, associated with the cyclone under study. This analysis is based on the archived outputs from the GoM-HYCOM simulation. As described in Sect. 3.1, this simulation uses 20 hybrid vertical layers. We first project the model outputs onto purely isopycnal layers, using the same number of layers, as well as the same target densities, as the native GoM-HYCOM grid. This choice leads to the interpolation of fields only from the layers that were not isopycnal in the HYCOM configuration, i.e., layers that were based on $z$ levels (mostly near the surface) and sigma layers near steep topography. The projection on purely isopycnal layers is necessary, because the PV calculation requires the knowledge of isopycnal layer thicknesses. The new fields in the purely isopycnal layers are interpolated linearly between adjacent depths from the original HYCOM grid. The fields in the new layer that is the closest to the surface are calculated based on the average of the original HYCOM archives, from the surface down to the bottom of that new layer, in order to keep most of the information on near-surface ocean parameters, as represented in the original HYCOM simulation.

This projection onto purely isopycnal layers leads to errors in the oceanic field estimates. In our case, the error in total depth-averaged current induced by this interpolation is on the order of $2 \%$ in areas deeper than $100 \mathrm{~m}$, whereas it is around $12 \%$ in areas shallower than $100 \mathrm{~m}$, with peaks reaching $25 \%$ at times. This larger value over shelf areas is likely due to the loss of information during the projection step, near the surface, or in low-stratified areas, where the use of isopycnal layers is less adapted than the original HYCOM $z$ levels. The small error in deep parts makes this analysis suitable for studying the PV evolution over the continental shelf slope and the deep ocean. In our case, this means that the PV analysis is well suited for studying PV anomalies evolving along the Campeche Bank slopes and in the Gulf interior.
We estimate the PV in each isopycnal layer, based on the interpolated currents, and the layer thicknesses:

$\mathrm{PV}=\frac{\varsigma+f}{h}$,

where $\zeta$ is the relative vorticity in the isopycnal layer, $f$ is the planetary vorticity, and $h$ the isopycnal layer thickness. We then examine the PV in each layer, in order to identify the layers that show the cyclone-related high-PV pole (one would look for a low-PV pole in the case of an anticyclone).

After identifying the layers showing high-PV pole associated with the cyclone under study (the CB2 eddy), we reduce the number of layers in order to simplify the analysis of the evolution of the PV field. Such a simplified approach was followed by Le Hénaff et al. (2012a) to investigate Loop Current Frontal Eddy PV intensification in the northern GoM. Layers are grouped consistently: here, isopycnal layers with a high-PV core corresponding to CB2 are grouped together, while other isopycnal layers are grouped separately. In our case, this method leads to a simplified analysis using only three layers (instead of 20), with an upper layer extending from 0 to 50 or $100 \mathrm{~m}$ in the study area; an intermediate layer under it where the high-PV core associated with CB2 was identified (which is about $100 \mathrm{~m}$ thick inside the eddy); and a deep layer below, extending to the bottom. In each of these new, simplified layers, we evaluate the corresponding currents by averaging all current values from the isopycnal layers that constitute the simplified layer. Using Eq. (A1), we can then derive the PV value in each of the simplified layer. This reduction of the number of layers allows an easier understanding of the evolution of the PV field, as it allows synthesizing the full description of the ocean by the model, based on dynamical considerations about the signature of the eddy under study. 
Acknowledgements. This research was funded by the $\mathrm{Na}-$ tional Science Foundation (NSF OCE - 0929651) and by the National Atmospheric and Oceanic Administration (NOAA NA13OAR4830224 and NA12OAR4310073). The Loop Current buoy data were kindly provided by P. Hamilton (Science Applications International Corporation: SAIC) and A. Lugo-Fernández (Bureau of Ocean Energy Management: BOEM). We are grateful to the productive collaboration with P. Hogan and O. M. Smedstad (Naval Research Laboratory-Stennis Space Center: NRL-SSC), who provided the GoM-HYCOM archives on the native model grid.

Edited by: J. M. Huthnance

\section{References}

Androulidakis, Y. S. and Kourafalou, V. H.: On the processes that influence the transport and fate of Mississippi waters under flooding outflow conditions, Ocean Dynam., 63, 143-164, 2013.

Athié, G., Candela, J., Ochoa, J., and Sheinbaum, J.: Impact of Caribbean cyclones on the detachment of Loop Current anticyclones, J. Geophys. Res., 117, C03018, doi:10.1029/2011JC007090, 2012.

Biggs, D., Fargion, G., Hamilton, P., and Leben, R.: Cleavage of a Gulf of Mexico Loop Current eddy by a deep water cyclone, J. Geophys. Res., 101, 20629-20620, 1996.

Candela, J., Sheinbaum, J., Ochoa, J., Badan, A., and Leben, R.,: The potential vorticity flux through the Yucatan Channel and the Loop Current in the Gulf of Mexico, Geophys. Res. Lett., 29, 2059, doi:10.1029/2002GL015587, 2002.

Canuto, V., Howard, A., Cheng, Y., and Dubovikov, M.: Ocean turbulence. Part I: One-point closure model-momentum and heat vertical diffusivities, J. Phys. Oceanogr., 31, 1413-1426, 2001.

Canuto, V., Howard, A., Cheng, Y., and Dubovikov, M.: Ocean turbulence. Part II: Vertical diffusivities of momentum, heat, salt, mass, and passive scalars, J. Phys. Oceanogr., 32, 240-264, 2002.

Chang, Y. L. and Oey, L. Y.: Why does the Loop Current tend to shed more eddies in summer and winter?, Geophys. Res. Lett., 39, L05605, doi:10.1029/2011GL050773, 2012.

Chérubin, L. M., Sturges, W., and Chassignet, E. P.: Deep flow variability in the vicinity of the Yucatan Straits from a highresolution numerical simulation, J. Geophys. Res., 110, C04009, doi:10.1029/2004JC002280, 2005.

Chérubin, L. M., Morel, Y., and Chassignet, E. P.: Loop Current ring shedding: the formation of cyclones and the effect of topography, J. Phys. Oceanogr., 36, 569-591, 2006.

Cochrane, J. D.: Separation of an anticyclone and subsequent developments in the Loop Current (1969), Contributions on the Physical Oceanography of the Gulf of Mexico, Tex. A\&M Univ., Oceanogr. Stud., 2, 91-106, 1972.

Cummings, J. A.: Operational multivariate ocean data assimilation, Q. J. Roy. Meteor. Soc., 131, 3583-3604, 2005.

Ertel, H.: Ein neuer hydrodynamischer Wirbelsatz, Meteorol. Z., 59, 277-281, 1942.

Ezer, T., Oey, L. Y., Lee, H. C., and Sturges, W.: The variability of currents in the Yucatan Channel: Analysis of results from a numerical ocean model, J. Geophys. Res., 108, 3012, doi:10.1029/2002JC001509, 2003.
Fratantoni, P. S., Lee, T. N., Podesta, G. P., and Muller-Karger, F. E.: The influence of Loop Current perturbations on the formation and evolution of Tortugas eddies in the southern Straits of Florida, J. Geophys. Res., 103, 24759, doi:10.1029/98JC02147, 1998.

Hamilton, P., Donohue, K., Leben, R., Lugo-Fernández, A., and Green, R.: Loop Current observations during spring and summer of 2010: Description and historical perspective, Geoph. Monog. Series, 195, 117-130, 2011.

Herbette, S., Morel, Y., and Arhan, M.: Erosion of a surface vortex by a seamount, J. Phys. Oceanogr., 33, 1664-1679, 2003.

Hurlburt, H. and Thompson, J. D.: A numerical study of Loop Current intrusions and eddy shedding, J. Phys. Oceanogr., 10, 1611-1651, 1980.

Hurlburt, H. E. and Thompson, J. D.: The dynamics of the Loop Current and shed eddies in a numerical model of the Gulf of Mexico, Oceanography Series 34, 243-297, 1982.

Ichiye, T.: Circulation and water mass distribution in the Gulf of Mexico, Geofis. Int., 2, 47-76, 1962.

Kennelly, M. A., Evans, R. H., and Joyce, T. M.: Small-scale cyclones on the periphery of a Gulf Stream warm-core ring, J. Geophys. Res., 90, 8845-8857, 1985.

Kourafalou, V. H., Peng, G., Kang, H., Hogan, P. J., Smedstad, O. M., and Weisberg, R. H.: Evaluation of global ocean data assimilation experiment products on south florida nested simulations with the hybrid coordinate ocean model, Ocean Dynam., 59, 47-66, 2009.

Kourafalou, V. H. and Kang, H.: Florida Current meandering and evolution of cyclonic eddies along the Florida Keys Reef Tract: are they inter-connected?, J. Geophys. Res., 117, C05028, doi:10.1029/2011JC007383, 2012.

Le Hénaff, M., Kourafalou, V. H., Morel, Y., and Srinivasan, A.: Simulating the dynamics and intensification of cyclonic Loop Current Frontal Eddies in the Gulf of Mexico, J. Geophys. Res., 117, C02034, doi:10.1029/2011JC007279, 2012a.

Le Heìnaff, M., Kourafalou, V. H., Paris, C. B., Helgers, J., Aman, Z. M., Hogan, P. J., and Srinivasan, A.: Surface Evolution of the Deepwater Horizon Oil Spill Patch: Combined Effects of Circulation and Wind-Induced Drift, Environ. Sci. Technol., 46, 7267-7273, 2012b.

Leben, R.: Altimeter-derived Loop Current metrics, in: Circulation in the Gulf of Mexico: Observations and Models, edited by: Sturges, W. and Lugo-Fernandez, A., American Geophysical Union, 181-201, 2005.

Mariano, A., Kourafalou, V., Srinivasan, A., Kang, H., Halliwell, G., Ryan, E., and Roffer, M.: On the modeling of the 2010 Gulf of Mexico Oil Spill, Dynam. Atmos. Oceans, 52, 322-340, 2011.

Martínez-López, B. and Zavala-Hidalgo, J.: Seasonal and interannual variability of cross-shelf transports of chlorophyll in the Gulf of Mexico, J. Marine Syst., 77, 1-20, 2009.

Meunier, T., Rossi, V., Morel, Y., and Carton, X.: Influence of bottom topography on an upwelling current: Generation of long trapped filaments, Ocean Model., 35, 277-303, 2010.

Oey, L. Y.: Simulation of mesoscale variability in the Gulf of Mexico: Sensitivity studies, comparison with observations, and trapped wave propagation, J. Phys. Oceanogr., 26, 145-175, 1996.

Oey, L. Y.: Loop Current and deep eddies, J. Phys. Oceanogr., 38, 1426-1449, 2008a. 
Oey, L. Y., Ezer, T., and Lee, H. C.: Loop current, rings and related circulation in the Gulf of Mexico: A review of numerical models and future challenges, in: Circulation in the Gulf of Mexico: Observations and Models, edited by: Sturges, W. and LugoFernandez, A., American Geophysical Union, 31-56, 2005.

Paris, C. B., Le Hénaff, M., Aman, Z., Suramaniam, A., Helgers, J., Wang, D. P., Kourafalou, V. H., and Srinivasan, A.: Evolution of the Macondo Well Blowout: Simulating the Effects of the Circulation and Synthetic Dispersants on the Subsea Oil Transport, Environ. Sci. Technol., 46, 13293-13302, doi:10.1021/es303197h, 2012.

Pearson, K.: Mathematical contributions to the theory of evolution. XI. On the influence of natural selection on the variability and correlation of organs, Philos. T. R. Soc. Lond., 200, 1-66, 1903.

Prasad, T. and Hogan, P. J.: Upper-ocean response to Hurricane Ivan in a 1/25 nested Gulf of Mexico HYCOM, J. Geophys. Res., 112, C04013, doi:10.1029/2006JC003695, 2007.

Rio, M., Guinehut, S., and Larnicol, G.: New CNES-CLS09 global mean dynamic topography computed from the combination of GRACE data, altimetry, and in situ measurements, J. Geophys. Res., 116, C07018, doi:10.1029/2010JC006505, 2011.

Rossi, V., Morel, Y., and Garcon, V.: Effect of the wind on the shelf dynamics: formation of a secondary upwelling along the continental margin, Ocean Model., 31, 51-79, doi:10.1016/j.ocemod.2009.10.002, 2010.

Schiller, R., Kourafalou, V., Hogan, P., and Walker, N.: The dynamics of the Mississippi River plume: Impact of topography, wind and offshore forcing on the fate of plume waters, J. Geophys. Res., 116, C06029, doi:10.1029/2010JC006883, 2011.

Schmitz Jr., W. J.: Cyclones and westward propagation in the shedding of anticyclonic rings from the Loop Current, Geoph. Monog. Series, 161, 241-261, 2005.
Sturges, W. and Evans, J. C.: On the variability of the Loop Current in the Gulf of Mexico, J. Mar. Res., 41, 639-653, 1983.

Sturges, W. and Leben, R.: Frequency of ring separations from the Loop Current in the Gulf of Mexico: A revised estimate, J. Phys. Oceanogr., 30, 1814-1819, 2000.

Stewart, S. R. and Cangialosi, J. P.: Eastern North Pacific Hurricane Season of 2010, Mon. Weather Rev., 140, 2769-2781, 2012.

Valentine, D. L., Mezic, I., Macesic, S., Crnjaric-Zic, N., Ivic, S., Hogan, P. J., Fonoberov, V. A., and Loire, S.: Dynamic autoinoculation and the microbial ecology of a deep water hydrocarbon irruption, P. Natl. Acad. Sci. USA, 109, 20286-20291, doi:10.1073/pnas.1108820109, 2012.

Von Arx, W., Bumpus, D., and Richardson, W.: On the fine-structure of the Gulf Stream front, Deep-Sea Res. Pt. II, 3, 46-65, 1955.

Vukovich, F. M. and Maul, G. A.: Cyclonic eddies in the eastern Gulf of Mexico, J. Phys. Oceanogr., 15, 105-117, 1985.

Walker, N. D., Pilley, C., Raghunathan, V., D'Sa, E., Leben, R., Hoffmann, N., Brickley, P., Co-holan, P., Sharma, N., Graber, H., and Turner, R.: Impacts of Loop Current frontal cyclonic eddies and wind forcing on the 2010 Gulf of Mexico oil spill, Geoph. Monog. Series, 195, 103-116, 2011.

Zamudio, L. and Hogan, P. J.: Nesting the Gulf of Mexico in Atlantic HYCOM: oceanographic processes generated by Hurricane Ivan, Ocean Model., 21, 106-125, 2008.

Zavala-Hidalgo, J., Morey, S. L., and O'Brien, J. J.: Cyclonic eddies northeast of the Campeche Bank from altimetry data, J. Phys. Oceanogr., 33, 623-629, 2003.

Zavala-Hidalgo, J., Gallegos-García, A., Martínez-López, B., Morey, S. L., and O'Brien, J. J.: Seasonal upwelling on the western and southern shelves of the Gulf of Mexico, Ocean Dynam., 56, 333-338. 2006. 